Federal Reserve Bank of Dallas

Globalization and Monetary Policy Institute

Working Paper No. 53

http://www.dallasfed.org/assets/documents/institute/wpapers/2010/0053.pdf

\title{
Trends in U.S. Hours and the Labor Wedge ${ }^{*}$
}

\author{
Simona E. Cociuba \\ Federal Reserve Bank of Dallas \\ Alexander Ueberfeldt \\ Bank of Canada
}

June 2010

\begin{abstract}
From 1980 until 2007, U.S. average hours worked increased by thirteen percent, due to a large increase in female hours. At the same time, the U.S. labor wedge, measured as the discrepancy between a representative household's marginal rate of substitution between consumption and leisure and the marginal product of labor, declined substantially. We examine these trends in a model with heterogeneous households: married couples, single males and single females. Our quantitative analysis shows that the shrinking gender wage gaps and increasing labor income taxes observed in U.S. data are key determinants of hours and the labor wedge. Changes in our model's labor wedge are driven by distortionary taxes and non-distortionary factors, such as cross-sectional differences in households' labor supply and productivity. We conclude that the labor wedge measured from a representative household model partly reflects imperfect household aggregation.
\end{abstract}

JEL codes: E24, H20, H31, J22

\footnotetext{
Simona Cociuba, Research Department, 2200 N. Pearl Street, Dallas, TX 75201. simona.cociuba@gmail.com. Alexander Ueberfeldt, Canadian Economic Analysis Department, 234 Wellington Street, Ottawa, Ontario, Canada K1A 0G9. 1-613-782-7839. aueberfeldt@bankofcanada.ca. The authors thank Jim Dolmas, Lutz Hendricks, Gueorgui Kambourov, Narayana Kocherlakota, Mark Wynne and Carlos Zarazaga for their helpful comments. The views expressed in this paper are those of the authors and do not necessarily reflect the views of the Bank of Canada, the Federal Reserve Bank of Dallas or the Federal Reserve System.
} 


\section{Introduction}

From the early 1980s to 2007, U.S. average hours worked, defined as the total hours worked in the marketplace relative to the population of working age, increased by thirteen percent. During the same time period, the U.S. labor wedge, measured as the discrepancy between a representative household's marginal rate of substitution between consumption and leisure and the marginal product of labor, declined substantially. In this paper, we show that allowing for heterogeneous households in an otherwise standard growth model is key in accounting for these trends.

In many models used to analyze changes in hours worked, an intratemporal labor equilibrium condition governs the time allocation decision. This condition, which equates the marginal rate of substitution between consumption and leisure $(M R S)$ to the marginal product of labor $(M P L)$, typically does not hold in the data. Consequently, these models' predictions for hours worked do not match the data. Mulligan (2002), Prescott (2004), and Ohanian, Raffo, and Rogerson (2008) show that the discrepancy measured in the data between the $M R S$ and the $M P L$ - the labor wedge - can partly be accounted for by taxes. For many countries, taking changes in consumption and labor income tax rates into account improves the model's predictions for hours worked. ${ }^{1}$ The U.S. is an exception. As shown in the studies cited above, the increase in U.S. average hours worked and the decline in the U.S. labor wedge are puzzling from the perspective of a standard neoclassical growth model because they were accompanied by a significant increase in labor income taxes. Given higher taxes, the model predicts lower hours worked, and a higher labor wedge. ${ }^{2}$

\footnotetext{
${ }^{1}$ For example, Prescott (2004) and Ohanian, Raffo, and Rogerson (2008) show that most of the variations in hours worked over time and across countries can be accounted for by differences in taxes. The tax rate used in their analysis for each country is a combination of consumption and labor income taxes, and is referred to as the effective tax rate on labor income (for more details, see Section 4.1). High levels of hours worked are typically observed in countries or in periods of time in which effective labor income taxes are low. One of the exceptions pointed out in the literature are Scandinavian countries where both tax rates and hours worked are high (see Ragan (2006) and Rogerson (2007)). Another exception - the U.S. experience since the 1960s - is analyzed in this paper.

${ }^{2}$ Several hypotheses have been put forward in order to reconcile the counterfactual predictions of the neoclassical growth model. Prescott (2004) suggests that the flattening of the income tax rate schedule in the 1980s plays an important role in accounting for the increase in U.S. labor supply. He conjectures that
} 
In this paper, we depart from the representative household assumption of the neoclassical growth model to examine the observed trends in U.S. hours and the labor wedge. Our analysis is motivated by the fact that all of the trend increase in U.S. market hours is due to women. Married women's hours more than doubled since the early 1960s, while the hours of single women rose slightly. In contrast, the hours of single and married men declined. We augment the neoclassical growth model by allowing for gender and marital status heterogeneity and consider the importance of several factors for hours and the labor wedge: reductions in gender wage gaps, increases in labor income taxes, changes in government consumption and changes in population. ${ }^{3}$ All of these factors are exogenous to the model and measured from U.S. data for the period 1960 to $2007 .{ }^{4}$ We find that reductions in gender wage gaps are key in accounting for the increase in women's hours, the increase in aggregate hours and the decline in the labor wedge. These model predictions arise in spite of the increase in taxes. The early 1980s marked a dramatic change for U.S. aggregate hours and the labor wedge. While both measures were fairly constant for the twenty years prior to 1980, afterwards hours increased and the labor wedge decreased significantly (see Figure 1). Our model's predictions are consistent with both pre- and post-1980 facts.

In our model, married couples, single women and single men make decisions on how to allocate their time between working in the marketplace and leisure. Women receive a lower hourly wage rate compared to men, due to lower productivity and discrimination

reductions in the marginal tax rate for two-earner households led to the observed rise in female participation and thus a rise in aggregate labor supply. However, Bar and Leukhina (2009) show that the tax reforms of 1980s had only a small effect on married females participation and conclude that other factors were more important. Ohanian, Raffo, and Rogerson (2008) suggest that changes in time devoted to home production may be important for the U.S. We discuss this in more detail in Section 5.2.

${ }^{3}$ In our numerical experiments, the gender wage gap for singles differs from the one for married couples, consistent with U.S. data. Moreover, we include both consumption and labor income taxes in our analysis in the measurement of the effective tax rate on labor income (as discussed in Section 4.1).

${ }^{4}$ Taxes, government consumption and population are typically treated as exogenous inputs in macroeconomic models. A few studies in the literature endogenize the gender wage gap. Erosa, Fuster, and Restuccia $(2002,2005)$ endogenize the married women's gender wage gap, by relating it to the human capital lost after child birth. In Jones, Manuelli, and McGrattan (2003) the gender wage gap is partly endogenous, due to human capital decisions, and partly exogenous, due to direct wage discrimination or to the existence of a "glass ceiling" that keeps women from rising in the hierarchy of organizations. 
(as suggested by Goldin (1992)). Moreover, the labor income of all households is taxed. ${ }^{5}$ The gender wage gap for single and married couples and labor income taxes are important determinants of hours worked and the labor wedge in the model. Shrinking gender wage gaps lead women to work more hours, while higher taxes result in lower hours worked for all households. In order to derive the model's implications for the labor wedge, we aggregate the intratemporal labor equilibrium conditions of all men and women in our model. The analytical expression obtained shows that the labor wedge depends not only on taxes, as suggested in previous studies, but also on other labor market variables such as gender wage gaps, female labor supply and aggregate labor supply. Higher taxes lead to an increase in the labor wedge, while shrinking gender wage gaps (reflecting lower discrimination or higher productivity of women or a combination of the two) result in a lower labor wedge. In our quantitative experiments, we evaluate the relative importance of these opposing forces for hours worked and the labor wedge.

A calibrated version of our baseline model - with gender wage gaps, taxes, government consumption and population measured from U.S. data-accounts for 63 percent of the increase in average hours worked and 86 percent of the increase in married women's hours. The baseline model accounts for about 30 percent of the decline in the U.S. labor wedge. We perform additional experiments to isolate the quantitative importance of each factor and show that the increase in hours and the decline in the labor wedge are driven by the shrinking of the gender wage gaps. Moreover, a model with changes in taxes alone is unable to account for any of the changes in U.S. hours or the labor wedge, consistent with previous studies.

We consider some extensions of our analysis and their implications for hours. Following

\footnotetext{
${ }^{5}$ In our quantitative experiments, the effective labor income tax (defined as in footnote 1 ) is the same for singles and married individuals, as well as for men and women. We have constructed estimates of average income taxes for single men, single women, married men and married women using the methodology in Kryvtsov and Ueberfeldt (2007). We find that while the level of the tax varies slightly, the increase in the income tax between 1961 and 2001 is comparable across groups. Moreover, as discussed in footnote 2, Bar and Leukhina (2009) find that the tax reforms of 1980s have a small effect on married females participation. For these reasons, we do not consider different tax rates for the different households in our model.
} 
Attanasio, Low, and Sánchez-Marcos (2008), we augment our model in order to quantify the impact of decreasing child care costs on women's labor supply. We find that reductions in this cost lead to increases in married women's hours and in aggregate hours. Quantitatively, this complements the predictions obtained from a model without child care costs, although we find the shrinking of the gender wage gaps to be more important. Moreover, we discuss the importance of taking into account changes in home production and leisure time, as suggested by Ohanian, Raffo, and Rogerson (2008). We show that while it helps improve the predictions of the model, this mechanism alone cannot account for all of the changes in U.S. hours.

As highlighted earlier, the increase in taxes observed in the U.S. economy hurts our model's predictions for both hours and the labor wedge. A variation of our baseline model in which taxes are held constant accounts for virtually all of the increase in aggregate and women's hours. In spite of very good predictions for hours, this experiment accounts for only two-thirds of the decline in the labor wedge. Our model is unable to account for all of the decline in the labor wedge, since it has difficulty capturing the increase in the consumption to output ratio observed in the U.S. since the mid 1980s.

Our paper makes two main contributions. First, we quantitatively evaluate the importance of shrinking gender wage gaps and increasing labor income taxes for U.S. labor supply. In doing so, we contribute to the existing literature that has highlighted the importance of gender wage gaps alone to women's labor supply (see e.g., Goldin (1992), Jones, Manuelli, and McGrattan (2003), Bar and Leukhina (2008) and Attanasio, Low, and Sánchez-Marcos (2008)). Second, we show that the labor wedge measured from a representative household model partly reflects imperfect household aggregation. Some previous papers in the literature interpret the labor wedge as an indicator of labor market distortions such as taxes, monopoly power, sticky wages, or search frictions (see e.g., Mulligan (2002), Chari, Kehoe, and McGrattan (2007), Shimer (2009)). In our heterogenous household model, the labor wedge is partly due to labor market distortions, such as taxes and discrimination, but partly 
due to non-distortionary factors, such as cross-sectional differences in households' labor supply and productivity. Our quantitative results confirm the finding that taxes do not help account for the decline in the U.S. labor wedge since the 1980s. Rather, it is changes in the relative productivity of men and women and changes in discrimination that contribute to reductions in the labor wedge.

While our paper focuses on long-run trends in hours and the labor wedge, many papers analyzing the labor wedge have focused on short-run fluctuations. For example, Parkin (1988) and Hall (1997) consider models with time-varying preferences and attribute changes in the labor wedge to shifts in preferences. Chari, Kehoe, and McGrattan (2007) show that in order to understand economic fluctuations in the U.S. it is important to understand changes in the labor wedge along with changes in total factor productivity. ${ }^{6}$ Shimer $(2009,2010)$ shows that the labor wedge rises in recessions and that models with search frictions and real wage rigidities generate an endogenous cyclical wedge between the $M R S$ and the $M P L$. Chang and Kim (2007) show that a heterogeneous-agent model economy with incomplete capital markets and indivisible labor is able to generate a labor wedge that has similar cyclical properties to the labor wedge measured from U.S. aggregate data. They suggest that part of the labor wedge is due to imperfect aggregation across different households, as we show here, in our analysis of the U.S. economy from the early 1960s to $2007 .{ }^{7}$

The paper is organized as follows. Section 2 documents the trend changes in U.S. hours and the labor wedge. We highlight that taking heterogeneity of the population into account is important in accounting for these trends. Section 3 presents our baseline model with gender and marital status heterogeneity. We derive the analytical expression for the model's labor wedge and discuss briefly the model's predictions for hours and the labor wedge. Section 4 presents the quantitative experiments and results. In Section 5, we consider other factors-

\footnotetext{
${ }^{6}$ Several other studies underscore the importance of the labor wedge in understanding economic fluctuations. See, for example, Ahearne, Kydland, and Wynne (2006) for a study of Ireland's recession in the 1980s, Kersting (2008) for a study of the 1980s recession in the United Kingdom, or Chakraborty (2009) for an analysis of the labor wedge in Japan's lost decade during the 1990s.

${ }^{7}$ Cociuba and Ueberfeldt (2008) analyze the Canadian labor wedge since the early 1960s. They show that the decline in the labor wedge can be tied to reductions in the gender wage gaps observed in Canada.
} 
such as changes in child care costs, leisure time and time devoted to home production - and discuss their relative importance for the trends observed in U.S. hours and the labor wedge. We conclude in Section 6.

\section{U.S. Data and a Simple Static Model}

In this section, we document trends in U.S. hours and the labor wedge. We use a simple model to highlight that taking into account heterogeneity of the population is key in understanding these trends.

\subsection{A Look at U.S. Data}

The changes in the aggregate weekly hours worked in the U.S. economy from 1961 to 2007 are documented in the upper left panel of Figure 1 (see Appendix $A .1$ for details on the data sources and computations). Throughout the 1960s and the 1970s, the U.S. working-age population worked, on average, 25 hours per week. Beginning in the early 1980s, aggregate hours increased steadily to 28 hours per week in $2007 . .^{8}$ The upper right panel of Figure 1 plots the average weekly hours worked for males and females, by marital status. We see that the increase in aggregate hours is driven by women. In 1961, married men worked an average of 39 hours per week, while single men worked 28 hours, single women worked 22 hours and married females worked only 10 hours. By 2007, men's hours declined by 4 to 10 percent, while women's hours increased. The largest increase was in the hours of married women, which more than doubled over the 47 year period. These differences in the hours worked by men and women motivate our model in Section 3.

The bottom panel of Figure 1 plots the labor wedge for the U.S. economy, normalized to equal 1 in year 1961. We follow the literature and measure the labor wedge as a discrepancy

\footnotetext{
${ }^{8}$ U.S. aggregate hours worked have declined during the recent recession, dated to start in December 2007 by the NBER. The changes in hours observed during these last few years are interesting in their own right, but are not analyzed in this paper.
} 
between the representative household in a neoclassical growth model and the aggregate U.S. data (see e.g., Parkin (1988), Hall (1997), Mulligan (2002), Chari, Kehoe, and McGrattan (2007) and Shimer (2009)). In particular, we start with the static model condition which equates the marginal product of labor $(M P L)$ to the marginal rate of substitution between consumption and leisure $(M R S)$. We use U.S. data to measure the $M P L$ and the $M R S$, and obtain the labor wedge as the residual that makes the model condition hold in the data. Many macroeconomic studies (including, but not limited to, the ones cited above) use a Cobb-Douglas production function. Then, the $M P L$ can be written as $(1-\theta) y_{t} / l_{t}$, where $y_{t}$ denotes output per person, $l_{t}$ denotes aggregate hours worked per person and $1-\theta$ is the labor income share. Time separable log preferences in consumption and leisure -frequently used in macroeconomic studies - give a $M R S$ equal to $\alpha\left(c_{t}+\phi g_{t}\right) /\left(1-l_{t}\right)$, where $c_{t}$ denotes private consumption per person, $g_{t}$ denotes public consumption per person, $\alpha$ is the leisure utility parameter and $\phi$ measures the marginal rate of substitution between government and private consumption. With these functional forms, the labor wedge, $\Delta_{t}$, is computed as follows:

$$
1-\Delta_{t} \equiv\left(\frac{\alpha\left(c_{t}+\phi g_{t}\right)}{1-l_{t}}\right) /\left(\frac{(1-\theta) y_{t}}{l_{t}}\right)
$$

where $c_{t}, g_{t}, y_{t}, l_{t}$ are taken from U.S. data, $\theta$ equals $0.33, \alpha$ is close to 1.6 (as in Prescott (2004)) and $\phi$ equals 1 (as in Prescott (2004) and Ohanian, Raffo, and Rogerson (2008)). ${ }^{9}$ As seen in Figure 1, the U.S. measured labor wedge is fairly constant for the period 1961 to 1980, and shows a trend decline between the early 1980s and 2007. This substantial decline in the labor wedge is also documented in Mulligan (2002) and Shimer (2010), under different functional forms for the marginal value of time $(M R S)$.

\subsection{Heterogeneity and the Labor Wedge}

We illustrate that heterogeneity is important in understanding the trend decline in the labor wedge. We present a simple static model with households of different productivities to build

\footnotetext{
${ }^{9}$ The values of the parameters $\theta, \alpha$ and $\phi$ are discussed in more detail in our quantitative results section.
} 
intuition. We show that the labor wedge is partly due to cross-sectional differences in the productivities of households. An immediate result is that changes in the labor wedge are not entirely driven by labor market distortions, such as taxes, but also reflect changes in nondistortionary factors, such as the labor supplies and relative productivities of various subgroups of the population. In other words, the labor wedge measured from a representative household model reflects imperfect aggregation.

The simple economy consists of different types of households indexed by $j$. Each household has one member who is endowed with one unit of time and has a fixed amount of capital given by $k_{j}$. Households supply labor in the market, but differ in their productivity, which is denoted by $z_{j}$. The maximization problem solved by household $j$ is:

$$
\begin{gathered}
\max _{c_{j}, l_{j}} \log \left(c_{j}+\phi g\right)+\alpha \log \left(1-l_{j}\right) \\
\text { subject to: } c_{j} \leq r k_{j}+\left(1-\tau_{l}\right) w z_{j} l_{j}+\psi_{j}
\end{gathered}
$$

The utility is defined over private consumption, $c_{j}$, government consumption per person, $g$, and leisure time, $1-l_{j}$, where $l_{j}$ is the fraction of available time devoted to work. Parameters $\alpha$ and $\phi$ are defined as before, in Section 2.1. Households receive wage rate $w$ per unit of effective labor, $z_{j} l_{j}$, and capital income $r k_{j}$ for renting the capital stock to the firm. Labor income is taxed at rate $\tau_{l}$, and $\psi_{j}$ are lump-sum transfers from the government.

The representative firm uses capital, $K$, and effective labor, $\tilde{L}$, to produce output according to the Cobb-Douglas production function: $Y=A K^{\theta} \tilde{L}^{1-\theta} \cdot{ }^{10}$ Here, $A$ denotes the total factor productivity, $K$ is the capital stock given by $K=\sum_{j} k_{j}$ and the effective labor is given by $\tilde{L}=\sum_{j}\left(z_{j} l_{j} N_{j}\right)$, where $N_{j}$ represents the number of households of type $j$. The wage rate per unit of effective labor is given by $w=(1-\theta) y / \tilde{l}$, where $y=Y / N$ is the output per person, $N=\sum_{j} N_{j}$ is the total population and $\tilde{l}=\tilde{L} / N$ is the aggregate effective labor

\footnotetext{
${ }^{10}$ We allow for capital stock in order for our derivations to be analogous to those presented in our general model in Section 3. However, the same intuition about the labor wedge presented in this section can be derived in an environment in which the production function uses only labor input.
} 
per person.

We show that in this simple model there exists a wedge between the aggregate marginal rate of substitution between consumption and leisure $(M R S)$ and the marginal product of an hour worked $(M P L)$. We start with the optimality condition which governs the consumption and time allocation decisions for each household $j: \alpha\left(c_{j}+\phi g\right) /\left(1-l_{j}\right)=\left(1-\tau_{l}\right) w z_{j}$. This condition equates the marginal rate of substitution of household $j$ to its after-tax marginal product of labor. Aggregating across households, we obtain: ${ }^{11}$

$$
\frac{\alpha(c+\phi g)}{1-l}=\left(1-\tau_{l}\right)\left(\sum_{j} z_{j} \frac{1-l_{j}}{1-l} \frac{N_{j}}{N}\right) \frac{l}{\tilde{l}} \cdot(1-\theta) \frac{y}{l}
$$

where $c \equiv \sum_{j} c_{j} N_{j} / N$ is aggregate private consumption per person, and $l \equiv \sum_{j}\left(l_{j} N_{j}\right) / N$ is aggregate hours worked per person, and where we have used the expression for the wage $w$. Using equation (2), the labor wedge, $\Delta$, is given by:

$$
1-\Delta \equiv\left(\frac{\alpha(c+\phi g)}{1-l}\right) /\left((1-\theta) \frac{y}{l}\right)=\left(1-\tau_{l}\right)\left(\sum_{j} z_{j} \frac{1-l_{j}}{1-l} \frac{N_{j}}{N}\right) \frac{l}{\tilde{l}}
$$

As seen in equation (3), the labor wedge is partly due to distortionary taxes, but also reflects non-distortionary factors such as the different productivities and labor decisions of each household in the economy. We provide a numerical illustration to show that heterogeneity of the working population matters for the labor wedge. In this example, the economy has two types of households of equal proportion in the population and there are no tax distortions (i.e. $\tau_{l}=0$ ). The labor supply, $l_{j}$, and productivity, $z_{j}$, of each type of household are presented in Table 1. In the first scenario, there are large differences in hours worked and productivity between the households. Type 2 households work only a quarter of the time per week and are 30 percent less productive compared to type 1 households. In this case, there is a wedge between the aggregate $M R S$ and the $M P L$ which is computed from equation (3)

\footnotetext{
${ }^{11}$ We multiply the individual optimality conditions by the fraction of agents of type $j$ in the total population, $N_{j} / N$, and sum up to get: $\alpha \sum_{j}\left(c_{j}+\phi g\right) N_{j} / N=\left(1-\tau_{l}\right) \sum_{j} z_{j}\left(1-l_{j}\right)\left(N_{j} / N\right) w$. Next, we substitute in the expression for the wage and divide both sides by $(1-l)$.
} 
and equals 0.13. For smaller differences in both hours and productivity, as shown in case 2, the labor wedge remains positive, but shrinks to about 0.02. Finally, if all households work the same hours (as in case 3), or have the same productivity (as in case 4), and because $\tau_{l}=0$ in our example, the labor wedge disappears. This result holds more generally. When $l_{j}=l$ for all $j$ or when $z_{j}=z$ for all $j$, the labor wedge in equation (3) reduces to $1-\tau_{l}{ }^{12}$

Next, we present our general model with households that differ by marital status, gender, and productivity and show that changes in non-distortionary factors are important for understanding the decline in the labor wedge.

\section{General Model}

In order to examine changes over time in U.S. hours and the labor wedge, we consider a neoclassical growth model with three types of households: married couples, single females, and single males. The labor supply decisions of individuals are influenced by several factors, of which the most important are gender wage gaps and effective labor income taxes.

Let $N_{t}$ be the total population at time $t$. Let $N_{p t}, N_{f s t}$, and $N_{m s t}$ denote the total number of married couples, single females and single males, respectively. Similar to Jones, Manuelli, and McGrattan (2003), we assume that individuals in a married couple solve for decisions efficiently. They choose streams of consumption, labor supply and investment to solve their joint decision problem with utility weights given by $\lambda_{f}$ and $\lambda_{m}$ :

$$
\max \sum_{t=0}^{\infty} \beta^{t}\left[\lambda_{f} U_{f}\left(c_{f p t}+\phi g_{t}, 1-l_{f p t}\right)+\lambda_{m} U_{m}\left(c_{m p t}+\phi g_{t}, 1-l_{m p t}\right)\right] N_{p t}
$$

subject to :

$$
\begin{aligned}
c_{f p t}+c_{m p t}+x_{p t} & \leq\left[\left(1-\tau_{k t}\right) r_{t}+\delta \tau_{k t}\right] k_{p t}+\left(1-\tau_{l t}\right) w_{t}\left[l_{m p t}+\left(1-\Gamma_{p t}\right) l_{f p t}\right]+\psi_{p t} \\
\frac{N_{p t+1}}{N_{p t}} k_{p t+1} & \leq x_{p t}+(1-\delta) k_{p t}
\end{aligned}
$$

\footnotetext{
${ }^{12}$ If $l_{j}=l$ for all $j$, then $\tilde{l}=l \cdot \sum_{j}\left(z_{j} N_{j}\right) / N$. Using equation (3), $1-\Delta=\left(1-\tau_{l}\right)\left(\sum_{j} z_{j} \frac{N_{j}}{N}\right) \frac{l}{\tilde{l}}=\left(1-\tau_{l}\right)$. Similarly, if $z_{j}=z$ for all $j$, then $\tilde{l}=z l$ and $1-\Delta=1-\tau_{l}$.
} 
where subscripts $f$ and $m$ denote female and male, subscript $p$ indicates a married couple or partnership, and $t$ is the time subscript. The utility of a married individual of gender $j \in$ $\{f, m\}$ is defined over streams of private consumption, $c_{j p t}$, average government consumption, $g_{t}$, and leisure time, $1-l_{j p t}$, where available time is normalized to 1 and $l_{j p t}$ is the labor supply expressed as the fraction of available time worked. The discount factor is $\beta \in(0,1)$. The parameter $\phi \in(0,1)$ measures the marginal rate of substitution between private and government consumption. The married couple owns capital stock, $k_{p t}$, which depreciates at rate $\delta$ and is augmented by investments, $x_{p t}$. The capital stock is rented to the firm at interest rate $r_{t}$, and the capital income net of depreciation is taxed at rate $\tau_{k t}$. The married couple also pays taxes on labor income at rate $\tau_{l t}$, and receives lump-sum transfers given by $\psi_{p t}$.

In our model, married males receive an hourly wage rate of $w_{t}$, while married females receive only $w_{t}\left(1-\Gamma_{p t}\right)$ per hour worked. Here, $\Gamma_{p t} \in(0,1)$ represents the gender wage gap for married couples, which is exogenous to the model. Motivated by existing evidence, we assume that women receive a lower wage for two reasons: productivity differences relative to men and discrimination. Goldin (1992) discusses in detail that some of the U.S. gender gap in earnings for various occupations can be explained by differences in observable attributes between men and women, such as job experience, education. However a substantial part of the earnings gap remains unexplained and is attributed to discrimination. ${ }^{13}$ In our model, we assume that productivity differences account for a fraction $\mu \in[0,1]$ of the gender wage gap, while discrimination accounts for the remainder. In particular, the hourly wage rate received by a married women can be written as:

$$
w_{t}\left(1-\Gamma_{p t}\right)=w_{t}\left(1-\mu \Gamma_{p t}\right)-w_{t}(1-\mu) \Gamma_{p t}
$$

where $w_{t}\left(1-\mu \Gamma_{p t}\right)$ is the wage rate women should receive given their marginal product

\footnotetext{
${ }^{13}$ For example, Goldin (1992) documents that wage discrimination was about 20 percent of the difference in male and female earnings in manufacturing jobs in early 1900, and about 55 percent for office work in 1940.
} 
of labor (i.e. taking into account productivity differences relative to men), while the term $w_{t}(1-\mu) \Gamma_{p t}$ represents the portion of the wage rate lost due to discrimination. Measures of wage discrimination from U.S. data - such as those discussed in Goldin - vary over time. For simplicity, we consider that the fraction of the gender gap accounted for by discrimination is constant over time in the model and is given by $1-\mu$. In Section 4 , we evaluate the importance of this assumption for female hours and the U.S. labor wedge by presenting results under two extreme scenarios: the gender wage gap is due entirely to discrimination or due entirely to productivity differences.

For $\mu \in(0,1)$, our model is consistent with the view that reductions in the gender gap observed in the U.S. since the early 1960s, were a consequence of productivity improvements of women and reductions in discrimination. As seen in equation (4), when the gender wage gap, $\Gamma_{p t}$, shrinks over time, the marginal product of a married women's labor, $w_{t}\left(1-\mu \Gamma_{p t}\right)$, increases, while the wages lost due to discrimination, $w_{t}(1-\mu) \Gamma_{p t}$, decline.

Single males and females solve the following maximization problem:

$$
\max \sum_{t=0}^{\infty} \beta^{t} U_{j}\left(c_{j s t}+\phi g_{t}, 1-l_{j s t}\right) N_{j s t}
$$

subject to :

$$
\begin{aligned}
c_{j s t}+x_{j s t} & \leq\left[\left(1-\tau_{k t}\right) r_{t}+\delta \tau_{k t}\right] k_{j s t}+\left(1-\tau_{l t}\right) w_{t}\left(1-I_{j} \Gamma_{s t}\right) l_{j s t}+\psi_{j s t} \\
\frac{N_{j s t+1}}{N_{j s t}} k_{j s t+1} & \leq x_{j s t}+(1-\delta) k_{j s t}
\end{aligned}
$$

where, as before, subscripts $j \in\{f, m\}$ and $t$ denote gender and time, and subscript $s$ indicates a single individual. We use similar notational conventions as in the married couple's problem. The indicator function $I_{j}$ equals 1 if $j=f$ and zero otherwise and is used to show that single males receive hourly wage rate $w_{t}$, while single females receive $\left(1-\Gamma_{s t}\right) w_{t}$. Here, $\Gamma_{s t} \in(0,1)$ represents the gender wage gap for singles. As before, the parameter $\mu$ governs the share of the gender wage gap accounted for by productivity differences.

Our model differentiates between males and females along two main dimensions. First, 
married and single females receive a lower wage than males. In the quantitative experiments, we allow the gender wage gap for singles and for married couples to differ, as in the data. As we show in later sections of the paper, reductions in the gender wage gap are important in accounting for the increase in female hours worked over time. The second difference between males and females in our model exists only for married couples and consists of the different utility weights $\lambda_{f}$ and $\lambda_{m} \equiv 1-\lambda_{f}$. In the quantitative experiments, the parameter $\lambda_{f}$ determines the relative level of hours worked for married men and women in the first period of our model (for details see Section 4).

There is a representative firm with a constant returns to scale production function that rents capital, $K_{t}$, and pays for effective labor, $\tilde{L}_{t}$. The firm's problem is:

$$
\begin{gathered}
\max F\left(K_{t}, \tilde{L}_{t}\right)-r_{t} K_{t}-w_{t} \tilde{L}_{t} \\
\text { subject to: } F\left(K_{t}, \tilde{L}_{t}\right)=K_{t}^{\theta}\left(\zeta_{t} \tilde{L}_{t}\right)^{1-\theta}
\end{gathered}
$$

There is labor augmenting technical progress at a constant yearly rate of $\gamma-1$, that is, $\zeta_{t}=\zeta_{0} \gamma^{t}$. The aggregate resource constraints for capital and effective labor are given by:

$$
\begin{aligned}
& K_{t}=k_{p t} N_{p t}+k_{f s t} N_{f s t}+k_{m s t} N_{m s t} \\
& \tilde{L}_{t}=l_{m p t} N_{p t}+\left(1-\mu \Gamma_{p t}\right) l_{f p t} N_{p t}+\left(1-\mu \Gamma_{s t}\right) l_{f s t} N_{f s t}+l_{m s t} N_{m s t}
\end{aligned}
$$

The wage bill in (5) is given by $w_{t} \tilde{L}_{t}$. Here, $w_{t}$ is the wage rate per unit of effective labor and also the wage rate per hour worked by men. In the expression for $\tilde{L}_{t}$, the terms $\left(1-\mu \Gamma_{i t}\right)$ for $i \in\{p, s\}$ measure the productivity of a married or single woman relative to men. Recall that women do not get paid their marginal product of $w_{t}\left(1-\mu \Gamma_{i t}\right)$, but receive the lower hourly wage rate of $w_{t}\left(1-\Gamma_{i t}\right)$ due to discrimination (as seen in equation (4) for married women). The difference between their marginal product and the wage rate received is equal to $w_{t}(1-\mu) \Gamma_{i t}$, and is collected by the government as revenue from discrimination. 
The resource constraint in the economy is given by: $F\left(K_{t}, \tilde{L}_{t}\right)=C_{t}+X_{t}+G_{t}$, where aggregate consumption is $C_{t} \equiv N_{p t}\left(c_{m p t}+c_{f p t}\right)+N_{m s t} c_{m s t}+N_{f s t} c_{f s t}$, aggregate investment is $X_{t} \equiv N_{p t} x_{p t}+N_{m s t} x_{m s t}+N_{f s t} x_{f s t}$ and $G_{t} \equiv N_{t} g_{t}$ denotes government spending. In the quantitative analysis, the government consumption is exogenous and is allowed to vary over time.

The government collects revenue from capital and labor income taxation. The revenue is used for government consumption expenditures and the remainder is lump-sum rebated to households. The lifetime budget constraint of the government is given by:

$$
\begin{gathered}
\sum_{t=0}^{\infty} \frac{1}{\pi_{t}}\left(\Psi_{t}+G_{t}\right)=\sum_{t=0}^{\infty} \frac{1}{\pi_{t}}\left\{\left[\tau_{k t} r_{t}-\delta \tau_{k t}\right] K_{t}+\Upsilon_{t}\right\} \\
\text { where } \pi_{t} \equiv\left\{\begin{array}{cc}
1 & \text { for } t=0 \\
\prod_{\varsigma=1}^{t}\left(1-\delta+R_{\varsigma}\right) & \text { for } t \geq 0
\end{array}\right.
\end{gathered}
$$

and where, $R_{t} \equiv\left(1-\tau_{k t}\right) r_{t}+\delta \tau_{k t}$, aggregate transfers are $\Psi_{t} \equiv N_{p t} \psi_{p t}+N_{f s t} \psi_{f s t}+$ $N_{m s t} \psi_{m s t}$, and aggregate labor revenues, $\Upsilon_{t}$, are defined as:

$$
\begin{aligned}
\Upsilon_{t} \equiv & {\left[\tau_{l t} w_{t} N_{p t} l_{m p t}+\tau_{l t} w_{t} N_{m s t} l_{m s t}+\tau_{l t}\left(1-\Gamma_{p t}\right) w_{t} N_{p t} l_{f p t}+\tau_{l t}\left(1-\Gamma_{s t}\right) w_{t} N_{f s t} l_{f s t}\right](7) } \\
& +\left[w_{t}(1-\mu) \Gamma_{p t} N_{p t} l_{f p t}+w_{t}(1-\mu) \Gamma_{s t} N_{f s t} l_{f s t}\right]
\end{aligned}
$$

Both men and women pay taxes on their labor income at rate $\tau_{l t}$. The revenues collected from this tax are given by the first four terms in equation (7). In addition, women's labor income is subject to discrimination which raises revenues equal to $w_{t}(1-\mu) \Gamma_{p t} N_{p t} l_{f p t}+$ $w_{t}(1-\mu) \Gamma_{s t} N_{f s t} l_{f s t}$.

In our quantitative experiments, we allow the effective labor income taxes, $\tau_{l t}$, the gender wage gaps, $\Gamma_{s t}$ and $\Gamma_{p t}$, the government consumption, $g_{t}$, and the population fractions, $n_{p t} \equiv$ $N_{p t} / N_{t}, n_{f s t} \equiv N_{f s t} / N_{t}, n_{m s t} \equiv N_{m s t} / N_{t}$, to vary exogenously over time. We allow the population fractions to vary since there has been a large increase in the fraction of singles 
and a corresponding decline in the fraction of married couples since 1961. All time-varying inputs are measured from U.S. data, as discussed in Section 4.

\subsection{Hours and the Labor Wedge in the Model}

Our model augments the representative household growth model presented in Prescott (2004) and Ohanian, Raffo, and Rogerson (2008) by considering labor supply decisions of men and women. In this section, we discuss why this extension brings the model's predictions closer to data. We also discuss briefly the counterfactual predictions of a representative household model for U.S. hours and the labor wedge. The quantitative results are presented in Section 4.

\subsubsection{Hours Worked}

We briefly discuss a few determinants of hours worked in our model. More details are provided in the results section.

Households in our model own the capital and rent it to the firm. Equivalently, we could allow the firm to buy the initial capital from the household and make capital investments thereafter. In other words, the consumption and labor supply decisions of households do not depend on who makes the capital investment. However, these decisions are affected by the household's initial wealth and the lump-sum transfers it receives over the lifetime. To

illustrate this, we aggregate the sequential budget constraints of singles of gender $j \in\{f, m\}$ into the following lifetime budget constraints.

$$
\begin{aligned}
\sum_{t=0}^{\infty} N_{j s t} \frac{1}{\pi_{t}} c_{j s t} \leq & \sum_{t=0}^{\infty} N_{j s t} \frac{1}{\pi_{t}}\left(1-\tau_{l t}\right) w_{t}\left(1-I_{j} \Gamma_{s t}\right) l_{j s t} \\
& +\sum_{t=0}^{\infty} N_{j s t} \frac{1}{\pi_{t}} \psi_{j s t}+N_{j s 0}\left(1-\delta+\left(1-\tau_{k 0}\right) r_{0}+\delta \tau_{k 0}\right) k_{j s 0}
\end{aligned}
$$

where $\pi_{t}$ is defined as in (6) and $I_{j}=1$ if $j=f$ and zero otherwise.

A similar lifetime budget constraint can be derived for the married couple as well. We 
see from equation (8) that aggregate lifetime transfers and the initial wealth due to the ownership of the capital stock influence the lifetime income of households, and thus, have an effect on the level of hours worked. Large lifetime transfers result in lower equilibrium hours for the household.

A key difference between the individuals in our model is the hourly wage rate they receive. If the gender wage gaps are zero (i.e. everyone receives the same wage and is equally productive), the men and women in our model make the same choices provided that $(i)$ initial wealth and lifetime transfers are proportional to the lifetime labor income of each household and $(i i)$ the individuals in the married couple have equal utility weights: $\lambda_{m}=\lambda_{f}$. Under these conditions, the model reduces to a representative household model with labor income taxes as in Prescott (2004) and Ohanian, Raffo, and Rogerson (2008). Then, the model predicts that everyone's hours are the same $l_{f p t}=l_{f s t}=l_{m s t}=l_{m p t}$ for all $t$. Moreover, an increase in the effective labor income tax leads to a decline in everyone's hours and, thus, in aggregate hours. This is consistent with the results of the two previous studies mentioned, but inconsistent with U.S. data which shows an increase in hours worked despite tax increases.

The model delivers more interesting predictions for hours worked when gender wage gaps are positive. All else equal, women in the model work fewer hours than men, and their hours grow over time as the gender wage gaps shrink. Both of these predictions are consistent with U.S. data. In Section 4, we evaluate the quantitative importance of taxes, gender wage gaps and other model features in accounting for the changes in U.S. hours worked.

\subsubsection{Aggregation and the Labor Wedge}

We derive the labor wedge in our model and show that it depends on taxes, as suggested by previous studies, but also on labor market variables such as gender wage gaps, female labor supply and the aggregate labor supply. The derivation is similar to that in Section 2 .

To obtain an expression for the labor wedge we aggregate the model's labor equilibrium 
conditions which are summarized in equation (9) for married and single men and in equation (10) for married and single women.

$$
\begin{aligned}
\frac{\alpha\left(c_{m i t}+\phi g_{t}\right)}{1-l_{m i t}} & =\left(1-\tau_{l t}\right) w_{t}, \text { for } i \in\{p, s\} \\
\frac{\alpha\left(c_{f i t}+\phi g_{t}\right)}{1-l_{f i t}} & =\left(1-\tau_{l t}\right)\left(1-\Gamma_{i t}\right) w_{t}, \text { for } i \in\{p, s\}
\end{aligned}
$$

We multiply each of the intratemporal conditions by the fraction of households of that type (i.e. fraction of married couples, $n_{p t}$, and fraction of singles, $n_{f s t}$ and $n_{m s t}$ ) and sum up to obtain equation $(11) \cdot{ }^{14}$

$$
\frac{\alpha\left(c_{t}+\phi g_{t}\right)}{1-l_{t}}=\left(1-\tau_{l t}\right)\left(1-\frac{n_{p t} \Gamma_{p t}\left(1-l_{f p t}\right)+n_{f s t} \Gamma_{s t}\left(1-l_{f s t}\right)}{1-l_{t}}\right) \frac{(1-\theta) y_{t}}{\tilde{l}_{t}}
$$

Here, $c_{t}=C_{t} / N_{t}$ denotes aggregate private consumption per person, $g_{t}=G_{t} / N_{t}$ denotes public consumption per person, $l_{t}=n_{p t} l_{m p t}+n_{p t} l_{f p t}+n_{m s t} l_{m s t}+n_{f s t} l_{f s t}$ denotes aggregate hours worked per person, $\tilde{l}_{t}=\tilde{L}_{t} / N_{t}$ denotes aggregate effective hours per person and $y_{t}=$ $F\left(K_{t}, \tilde{L}_{t}\right) / N_{t}$ denotes output per person.

Combining equation (11) with the definition of the labor wedge given in equation (1), we can rewrite $1-\Delta_{t}$ as in (12).

$$
1-\Delta_{t}=\left(1-\tau_{l t}\right)\left[1-\frac{n_{p t} \Gamma_{p t}\left(1-l_{f p t}\right)+n_{f s t} \Gamma_{s t}\left(1-l_{f s t}\right)}{1-l_{t}}\right] \frac{l_{t}}{\tilde{l}_{t}}
$$

The labor wedge, $\Delta_{t}$, depends on endogenous labor supply decisions of the households, as well as time-varying exogenous inputs of the model such as taxes, gender wage gaps and fractions of females in the total population. Notice that $\mu$-the parameter the governs the share of the gender wage gap accounted for by productivity differences - enters equation (12) indirectly through $\tilde{l}_{t}$. When $\mu=1$, the gender gap is due entirely to productivity differences between men and women. Then, changes in the labor wedge reflect changes in distortionary

\footnotetext{
${ }^{14}$ For a full derivation, see Appendix A.2.
} 
taxes, as well as changes in non-distortionary factors, such as the productivity of women, as discussed in the static example in Section 2. When $\mu=0$, the gender gap is due entirely to discrimination which can be interpreted as another distortion that affects the changes in the labor wedge.

In what follows, we briefly discuss the model's predictions for the labor wedge under various scenarios. A more detailed analysis is provided in the quantitative experiments section. First, consider the case when men and women earn the same wage (i.e. $\left.\Gamma_{p t}=\Gamma_{s t}=0\right)$. Equation (12) simplifies to: $1-\Delta_{t}=1-\tau_{l t}$, which means that the model's labor wedge is exogenously determined. As discussed in Section 3.1.1, the model reduces to a standard growth model with taxes, as in Prescott (2004) and Ohanian, Raffo, and Rogerson (2008). Since taxes, $\tau_{l t}$, increased in U.S. data in the last 50 years, the labor wedge, $\Delta_{t}$, generated under this scenario increases, contrary to what was observed in U.S. data.

Now consider the more interesting case in which the gender wage gaps are positive (i.e. $\left.\Gamma_{p t}>0, \Gamma_{s t}>0\right)$. For simplicity, assume that our model has only married couples and no single households, and that the gender wage gap is due entirely to discrimination. Equation (12) simplifies to: $1-\Delta_{t}=\left(1-\tau_{l t}\right)\left[1-0.5 \cdot \Gamma_{p t}\left(1-l_{f p t}\right) /\left(1-l_{t}\right)\right]$. Can the model deliver a labor wedge that declines over time as seen in U.S. data? Recall that since the early $1960 s$, the U.S. gender wage gap shrunk and taxes increased. If the model generates an increase in aggregate hours, $l_{t}$, and a larger increase in female hours, $l_{f p t}$, the term $\left[1-0.5 \cdot \Gamma_{p t}\left(1-l_{f p t}\right) /\left(1-l_{t}\right)\right]$ increases over time. In our quantitative analysis, we show that this increase dominates the decline in $\left(1-\tau_{l t}\right)$, and the model delivers a decline in the labor wedge, $\Delta_{t}$, over time (see Section 4.2 for details). 


\section{Quantitative Analysis}

We compute the equilibrium paths of our model and compare its predictions with U.S. data. In our baseline experiment, we treat the effective labor income taxes, the gender wage gaps, the government consumption and population fractions as exogenous, time-varying inputs. We perform other experiments to isolate the quantitative importance of each factor.

\subsection{Baseline Calibration}

Here, we present and motivate the model parameters and the exogenous series used as inputs in the quantitative experiments. We choose parameters so that our baseline model matches key statistics of the U.S. economy. We use national accounts and fixed assets data, revenue statistics and survey data for the U.S. as described in detail in Appendix A.1. Unless otherwise noted, we use data for the years 1961 to 2007. The parameters and time-varying inputs are summarized in Table 2 and Figure 2.

First, we discuss the measurement of the time-varying exogenous inputs of our model. The effective labor income taxes are defined as in Prescott (2004) and Shimer (2009). In particular, $\tau_{l t}=1-\left(1-\tau_{h t}\right) /\left(1+\tau_{c t}\right)$, where $\tau_{h t}$ and $\tau_{c t}$ are the labor income tax rate and the consumption tax rate which are constructed following the methodology of Mendoza, Razin, and Tesar (1994). The interpretation of this effective tax is that one additional unit of pre-tax labor income buys $\left(1-\tau_{h t}\right) /\left(1+\tau_{c t}\right)$ units of consumption, after labor and consumption taxes are paid for. The government-consumption to output ratio is constructed using national accounts data. The gender wage gaps for married and single individuals, $\Gamma_{p t}$ and $\Gamma_{s t}$, are measured using microdata from the Current Population Survey (CPS) as detailed in the data appendix. Finally, the population fractions, $n_{p t}, n_{f s t}, n_{m s t}$, are also measured from the CPS.

We choose $\eta$ to match the average population growth rate and $\gamma$ to match the average growth rate of labor augmenting technical change over the 47 year period. We choose $\theta$ and 
$\delta$ to match the average capital income share and the average depreciation rate, respectively. We set $\tau_{k}$ to the average capital income tax for the U.S. since 1970. The discount factor is chosen to match a steady state after-tax net return $\left(1-\tau_{k}\right) r^{*}+\delta \tau_{k}-\delta$ of 4 percent.

We use the following utility function: $U_{f}=U_{m}=U=\frac{1}{1-\sigma}\left\{\left[(c+\phi g) \cdot(1-l)^{\alpha}\right]^{1-\sigma}-1\right\}$. We follow Prescott (2004) and Ohanian, Raffo, and Rogerson (2008) and set the intertemporal substitution parameter, $\sigma$, and the government consumption parameter, $\phi$, to 1 . The leisure parameter, $\alpha$, and the utility weights in the married couple's problem, $\lambda_{f}$ and $\lambda_{m} \equiv 1-\lambda_{f}$, are calibrated as follows. First, note that $\alpha$ affects the level of hours of all individuals in the economy, as well as the level of aggregate hours. The utility weights $\lambda_{f}$ and $\lambda_{m}$ influence the relative level of hours for married males and females. We pick $\alpha$ and $\lambda_{f}$ so that the aggregate labor supply and married female labor supply in the initial period in the model are consistent with U.S. data on hours worked in 1961. Recall that labor supply in the model is expressed as a fraction of available time worked. Given 100 hours of available time per week, the aggregate weekly hours worked in the model are $l_{t} \cdot 100$ and married female weekly hours worked are $l_{f p t} \cdot 100$. Our calibration ensures that $l_{1961} \cdot 100$ equals 24.6 hours and $l_{f p 1961} \cdot 100$ equals 10.3 hours, as observed in U.S. data in 1961. Once $\alpha$ and $\lambda_{f}$ are calibrated, the levels of hours for the other individuals for the year 1961 are determined in equilibrium.

As discussed in Section 3.1.1, the initial capital stock wealth and lifetime transfers have an impact on the level of hours of each household. We set initial wealth of each household, $k_{p 0}, k_{f s 0}$ and $k_{m s 0}$, to be proportional to labor income in 1961 . We set lifetime transfers to be proportional to the total income (labor income plus initial capital stock wealth) earned by each household in the model. This choice of distributing transfers preserves the ratios of lifetime income between the three groups of households.

In our baseline calibration, we assume that the gender gap is entirely due to discrimination (i.e. $\mu=0$ ). We later perform a sensitivity analysis to this choice by considering how our results change when the gender gap is accounted for entirely by productivity differences 
between males and females (i.e. $\mu=1$ ).

\subsection{Results}

We evaluate the extent to which the model is able to replicate trends in average hours worked for the different population groups relative to the U.S. data. We measure the labor wedge generated in the model - as the aggregate discrepancy between the marginal rate of substitution between consumption and leisure and the marginal product of labor - and examine whether it is consistent with U.S. data. We report results from multiple experiments in order to isolate the relative importance of the different factors considered: taxes, gender wage gaps, government consumption ratio and population fractions. In Section 5, we discuss other factors that may be important for labor supply, such as child care costs, home production and leisure time.

Our baseline model allows all exogenous inputs - taxes, gender wage gaps, government consumption ratio and population fractions - to vary over time as seen in U.S. data (see Figure 2). The results for hours worked and the labor wedge are reported in Figure 3. The solid lines in the left side panels of the figure show weekly hours worked by males and females in the U.S. economy between 1961 and 2007. The dashed lines show the baseline model results for hours worked (e.g. for married males, we plot $l_{m p t} \cdot 100$ where $l_{m p t}$ is the fraction of time worked and 100 represents the available hours per week). The model is quite successful in matching the level of hours and in accounting for the changes in hours over time. Recall that aggregate hours and married females hours for the year 1961 are matched through the choice of $\alpha$ and $\lambda_{f}$. The levels of hours worked for married males, single males and single females for the year 1961 are not pinned down in the calibration, but are determined in equilibrium. While the model does not match these levels exactly, it does deliver the same ranking of hours among the different population groups as in the data for the year 1961. For example, in the data, a single male worked about $26 \%$ more than a single female in year 1961, while the comparable figure in the model was $25 \%$. 
The upper right panel of Figure 3 plots aggregate weekly hours worked in the data and in the baseline model (variable $l_{t}$ ). The model predicts correctly very little changes in hours between 1960 and 1980, and an increase in hours afterwards. In the data, the overall increase in hours since 1960 was 13.3 percent, while the model delivers an increase of $8.4 \%$. An obvious discrepancy between the model and the data is seen during the 1990s. In the data, aggregate hours worked increase, while the model predicts a decline during this period due to the increase in observed taxes. ${ }^{15}$ Lastly, as seen in the lower right panel of Figure 3, the model delivers a decline in the labor wedge since the early 1980s.

More detailed results from the baseline model are shown in Tables 3 and 4. Table 3 presents a detailed comparison of hours in the data and the model. Using the expression for $l_{t}$, changes in aggregate hours worked per person between 1961 and 2007 can be decomposed as:

$$
\frac{l_{2007}}{l_{1961}}=\frac{n_{p 2007} l_{m p 2007}}{l_{1961}}+\frac{n_{m s 2007} l_{m s 2007}}{l_{1961}}+\frac{n_{f s 2007} l_{f s 2007}}{l_{1961}}+\frac{n_{p 2007} l_{f p 2007}}{l_{1961}}
$$

The contribution of each group of the population - married males, married females, single females and married females - can be decomposed further into the change in the fraction of the population in the group, the group's share in aggregate hours in 1961 and the change in the group's hours between 1961 and 2007. For example, for single females we have:

$$
\frac{n_{f s 2007} l_{f s 2007}}{l_{1961}}=\left(\frac{n_{f s 2007}}{n_{f s 1961}}\right) \cdot\left(\frac{n_{f s 1961} \cdot l_{f s 1961}}{l_{1961}}\right) \cdot\left(\frac{l_{f s 2007}}{l_{f s 1961}}\right)
$$

The baseline model matches the decomposition of aggregate hours well, as seen in Table 3. The fractions of married couples and singles in the total population are exogenous inputs into the baseline model, which means that changes in these fractions are matched exactly. Regarding the distribution of hours in U.S. data, in 1961 married men accounted for about 64 percent of hours worked, single men and women accounted for about 9.7 percent each,

\footnotetext{
${ }^{15}$ This counterfactual prediction for hours worked during the 1990s is also present in a standard growth model with a representative household. McGrattan and Prescott (2010) show that the U.S. hours boom observed in the 1990s is no longer puzzling after accounting for intangible investment.
} 
and married women for about 17 percent. In the model, the share of hours of each group in the aggregate hours is tightly linked to their predicted level of hours in the initial period. For example, singles contribute slightly more to aggregate hours in 1961 compared to the data, because the model predicts slightly higher hours for them in 1961 (see Figure 3). By the same token, the share of hours of married females in aggregate hours are matched almost exactly. Regarding changes in hours, the model predicts that hours worked by males fall by more than in the data, but hours worked by females increase similarly to what was observed.

Table 4 presents details on the model's labor factor, $1-\Delta_{t}$. Although for most of the paper we discuss changes in the labor wedge, $\Delta_{t}$, Table 4 focuses on the labor factor because its changes over time can be decomposed into several multiplicative components. First, using equation (1) and $\phi=1$, we can decompose changes in the labor factor into two components: the consumption to output ratio, $\left(c_{t}+g_{t}\right) / y_{t}$ and an aggregate labor component (or an aggregate labor to leisure ratio), $l_{t} /\left(1-l_{t}\right)$. Notice that changes over time in the labor factor do not depend on the leisure parameter, $\alpha$, or on the capital income share, $\theta$. Our baseline model predicts an increase of 6.6 percent in the labor factor (which is equivalent to a decline of about 10.5 percent in the labor wedge). All of the increase in the model's labor factor is driven by an increase in the aggregate labor component, while the model's consumption to output ratio declines. When measured using U.S. data, the labor factor increases by more between 1961 and 2007, partly due to an increase in the consumption to output ratio, and partly due to a larger increase in the aggregate labor component. This decomposition underscores one of the counterfactual predictions of the model: the consumption to output ratio declines in the model while it increased in U.S. data. Later in this section, we show that this result holds in multiple experiments and that the model is unable to deliver both an increase in aggregate hours and an increase in the consumption to output ratio, as observed in U.S. data.

A second decomposition of the labor factor from our baseline model makes use of equation (12) and is also presented in Table 4. Changes in the labor factor are now determined by 
changes in a tax rate component, $1-\tau_{l t}$, and changes in a female labor component given by $1-\frac{n_{p t} \Gamma_{p t}\left(1-l_{f p t}\right)+n_{f s t} \Gamma_{s t}\left(1-l_{f s t}\right)}{1-l_{t}}$. Recall that the baseline model attributes all of the gender wage gaps to discrimination (i.e. $\mu=0$ ), which means that the labor input equals the effective labor (i.e. $l_{t} / \tilde{l}_{t}=1$ ). The first lesson from this decomposition is that the increase of 6.6 percent in the labor factor in the baseline model is driven entirely by the female labor component. The effective tax rate component, $1-\tau_{l t}$, is exogenous to the model and leads to a decline in the labor factor. The female labor component depends on inputs that are exogenous to the model, such as gender wage gaps and fractions of females in the population, but also on endogenous labor supply decisions of women and on the average labor supply. In the model, this component increases by about 15 percent over time, which is close to the increase obtained when we evaluate the expression using U.S. data. The bottom line from Table 4 is that a model with changes in gender wage gaps only, and no changes in effective taxes will predict a larger increase in the labor factor (or a larger decline in the labor wedge). This result is illustrated further in a separate experiment.

We perform additional experiments to show that the closing of the gender wage gaps are an important driving force for our results. Unless otherwise noted, we use the same parameters in these experiments as given in Table 2. In Figure 4, we plot the results from an experiment in which only gender wage gaps are allowed to vary over time, as measured from U.S. data. All other exogenous inputs shown in Figure 2 are held fixed at their 1961 levels. Overall, the predictions from this experiment for hours of males and females, as well as aggregate hours are closer to U.S. data. The main reason for the improved predictions is that effective income tax rates do not vary over time. As a result, the model predicts a smaller decline in male hours and a slightly larger increase in females hours compared to the baseline model. Moreover, the labor wedge declines by nearly twice as much as in the baseline experiment. The main difference is again due to taxes.

Figure 5 reports results from an experiment in which the gender wage gaps are held fixed at their 1961 levels. All other exogenous inputs - taxes, government consumption ratio and 
fractions of households - shown in Figure 2 are allowed to vary over time. Without shrinking gender wage gaps, the model fails to generate increases in women's hours worked. In fact, hours worked for all groups decline marginally over time due to increases in effective labor income taxes. As a result, the model fails to capture the observed increase in aggregate hours worked. Moreover, the increase in the labor wedge is inconsistent with U.S. data. The predictions of this experiment are similar to the predictions of a standard growth model with a representative household and time-varying taxes.

Some additional experiments are summarized in Table 5 and compared with the experiments we already discussed. We present predictions for aggregate hours, $l_{t}$, married women's hours, $l_{f p t}$, the labor wedge, $\Delta_{t}$, and the consumption to output ratio, $\left(c_{t}+g_{t}\right) / y_{t}$. First, note that neither of the experiments can account for the increase in the consumption to output ratio observed in the data. This result affects negatively the predictions for the labor wedge as discussed earlier (see Table 4). Our baseline model accounts for about 63 percent of the increase in aggregate hours worked per week, 83 percent of the increase in married women's hours, while it accounts for only 30 percent of the decline in the labor wedge. Among the experiments with only one time-varying input, the experiment with changes in gender wage gaps performs the best. It accounts for 95 percent of the increase in aggregate hours and about 54 percent of the decline in the labor wedge. The experiment with changes in effective taxes alone has counterfactual predictions for labor supply and for the labor wedge. The experiment in which we allow only the fractions of married couples and singles to vary over time delivers an increase in labor supply, but for the wrong reasons. In this experiment, the hours of all individuals increase slightly over time. The increase in the model's aggregate hours is then driven mainly by singles, since the fractions of singles increases significantly between 1961 and 2007, as observed in U.S. data.

In all experiments discussed so far, we have assumed that males and females are equally productive, and the gender wage gaps are due entirely to discrimination (i.e. $\mu=0$ ). We perform an experiment in which all exogenous inputs are allowed to vary over time, but we 
assume the gender wage gaps are due entirely to productivity differences between females and males (i.e. $\mu=1$ ). We recalibrate parameters $\alpha$ and $\lambda_{f}$ to match the same targets on hours worked as in the baseline calibration, but keep all other parameters unchanged. We find that a model with $\mu=1$ implies fairly similar changes in hours worked for males and females. Aggregate hours go up by 7.4 percent compared to 8.4 percent in the baseline model. The decline in the labor wedge is smaller in this experiment compared to the baseline. Recall that using equation (12) the labor factor, $1-\Delta_{t}$, can be decomposed in three factors as shown at the bottom of Table 4 . When $\mu=1$, the ratio $l_{t} / \tilde{l}_{t}$ is less than one, leading to smaller increases (decreases) in the labor factor (labor wedge). ${ }^{16}$ We thus conclude that the particular choice of $\mu$ - the fraction of the gender wage gaps accounted for by productivity differences - does not overturn our conclusion that the gender wage gap is an important driving force behind the long-run changes in U.S. labor supply over the period 1961 to 2007.

\section{Other Considerations}

We have shown that reductions in the gender wage gap for married couples and singles are important in accounting for the increase in female hours worked observed in the U.S. Our model successfully delivers an increase in U.S. hours worked and a decline in the U.S. labor wedge, despite the observed increase in effective labor income taxes. In this section, we consider other factors that may have an impact on hours worked, and the U.S. labor wedge.

\subsection{Changes in Child Care Costs}

Attanasio, Low, and Sánchez-Marcos (2008) show that reductions in child care costs along with reductions in the gender wage gap over time help explain the increase in participation

\footnotetext{
${ }^{16}$ Our results are approximately linear in the value of $\mu$. The results from our baseline experiment (which has $\mu=0$ ) and from the experiment with $\mu=1$ provide upper and lower bounds on how successful the model is. For example, an experiment in which all exogenous inputs are allowed to vary over time, but the value of $\mu$ equals 0.5 , predicts that aggregate hours increase by 7.9 percent and the labor wedge declines by 9.4 percent. These values are about midway between the results from the baseline model and the experiment with $\mu=1$ (see Table 5).
} 
rates of females in the U.S. The idea is that in the past child care costs were very high and mothers stayed at home after birth to care for their children. Thus, the rise in married women's labor supply is really a story about their wages increasing, as well as the number of children and the child care costs decreasing.

We consider an extension of our baseline model that features reductions in child care costs. We model child care services as a cost paid by the married couple. The married female decides how many hours, $l_{f p t}$, to work given the wage rate, $\left(1-\Gamma_{p t}\right) w_{t}$, she receives and given the hourly cost of childcare services, $\chi_{t}$. The new sequential budget constraints of the married couple are:

$$
\begin{aligned}
& c_{f p t}+c_{m p t}+x_{p t} \leq {\left[\left(1-\tau_{k t}\right) r_{t}+\delta \tau_{k t}\right] k_{p t}+\left(1-\tau_{l t}\right) w_{t} l_{m p t} } \\
&+\left[\left(1-\tau_{l t}\right) w_{t}\left(1-\Gamma_{p t}\right)-\chi_{t}\right] l_{f p t}+\psi_{p t}
\end{aligned}
$$

The new resource constraint is:

$$
C_{t}+X_{t}+\Xi_{t}+G_{t}=F\left(K_{t}, \tilde{L}_{t}\right)
$$

where $\Xi_{t}$ are the total resources spent on child care: $\Xi_{t}=n_{p t} l_{f p t} \chi_{t}$.

The intratemporal condition for the married female changes to (13) while the other three intratemporal conditions remain unchanged.

$$
\frac{\alpha\left(c_{f p t}+\phi g_{t}\right)}{1-l_{f p t}}=\left(1-\tau_{l t}\right)\left(1-\Gamma_{p t}\right) w_{t}-\chi_{t}
$$

We perform an experiment that features all time-varying inputs from our baseline model, plus changes in child care costs. We recalibrate parameters $\alpha$ and $\lambda_{f}$, so that the model with child care costs matches the same targets for hours worked as discussed in the baseline calibration. ${ }^{17}$ We keep all other parameters unchanged. To set the level of $\chi_{t}$, we use

\footnotetext{
${ }^{17}$ Note that under the baseline calibration, a model with child care costs predicts that married women would work fewer hours relative to the model with no child care costs. This leads us to recalibrate parameters
} 
data provided by U.S. Census Bureau based on the Survey of Income and Program Participation. According to this survey, the average child care expenditures of families with employed mothers that pay for such services were $15 \%$ of the mother's income in the year $2004 .^{18}$ We pick $\chi_{2004}$ so the ratio of child care costs to the married woman's income, $\chi_{2004} /\left(w_{2004}\left(1-\Gamma_{p, 2004}\right)\right)$, equals 0.15. A more problematic issue is the measurement of the change in child care costs from early 1960 s to present. Attanasio, Low, and Sánchez-Marcos (2008) consider reductions in child care costs that range between $-5 \%$ to $-20 \%$. In our experiment, we used the midpoint of this range. We pick $\chi_{1961}$ such that the childcare costs, as a fraction of a married female's income, decline linearly by $12.5 \%$ between 1961 and 2004 .

The results of this experiment are plotted in Figure 6, against the baseline model (with no child care costs). As expected, reductions in child care costs contribute to the increase in hours worked by married females. In our baseline model, hours of married females increase by a factor of 2.08 between 1961 and 2007. Adding reductions in child care costs leads to an increase in married female hours by a factor of 2.2. The hours of all other individuals are comparable across the two experiments. As a result, aggregate hours increase by a bit more and the labor wedge declines by a bit more over the 47 year period (see Table 5).

We conclude that reductions in child care costs help contribute to the increase in the labor supply and the decline in the labor wedge observed in the U.S. since 1960s. However, their quantitative role is less prominent than that of the gender wage gap.

\subsection{Changes in Time Devoted to Home Production and Leisure}

Ohanian, Raffo, and Rogerson (2008) suggest that the counterfactual predictions of the neoclassical growth model for U.S. hours can potentially be reconciled by taking into account changes in the amount of time devoted to home production. In their representative agent model (as well as in the model presented in this paper), hours worked in the market and $\alpha$ and $\lambda_{f}$.

${ }^{18}$ These data are available at: http://www.census.gov/population/www/socdemo/childcare.html, under "Who's Minding the Kids? Child Care Arrangements: Summer 2006", Table 6. The child care expenditures provided by the survey are for families with children age 15 and younger. 
leisure time are mirror images of each other. In U.S. data, leisure time depends not only on time spent at work, but also on time spent in non-market activities such as home production. ${ }^{19}$ Therefore, a model that accounts for the decline in home production observed in the U.S. in the past 50 years has a better chance of matching the increase in U.S. hours worked.

In this section, we argue that taking into account changes in home production and leisure time helps improve the predictions of our models for U.S. hours and the labor wedge. However, from a quantitative point of view, this mechanism can only provide part of the story. To see this, consider the case in which our baseline model reduces to a standard growth model (i.e. all individuals are the same). The labor equilibrium condition, which relates the marginal rate of substitution between consumption and leisure to the marginal product of labor, is:

$$
\frac{\alpha\left(c_{t}+\phi g_{t}\right)}{\text { leisure }_{t}}=\left(1-\tau_{l t}\right)(1-\theta) \frac{y_{t}}{l_{t}}
$$

Now, consider an extension of the model where leisure $t \equiv 1-l_{t}-(\text { non-market hours })_{t}$. We ask: what is the change needed in leisure time in order for equation (14) to be consistent with the data? Using previously mentioned U.S. data on taxes, private and public consumption, output and hours worked, we know that $\left(1-\tau_{l t}\right)$ declines by $7.5 \%,\left(c_{t}+g_{t}\right) / y_{t}$ increases by $6.8 \%$ and hours worked increase by $13.3 \%$ between 1960 and 2007 . Then, leisure time would need to increase by 31\%(=1.068*113.3/92.5 - 1) between 1960 and 2007 in order for equation (14) to hold.

The evidence regarding change in leisure time since 1960 is a bit mixed. Ramey and Francis (2009) document that time devoted to leisure activities changed fairly little between 1960 and 2005. For males between the ages of 25 and 54, they document a decline in average weekly hours worked, and an increase in time spent in home production between 1960 and 2005 (see Tables 2 and 4 in their paper). Over the same time period, females in the same age group increased their weekly hours worked, while reducing the time spent in home

\footnotetext{
${ }^{19}$ There are many papers in the literature that focus on home production and time devoted to this nonmarket activity, including, but not limited to, Benhabib, Rogerson, and Wright (1991), Ingram, Kocherlakota, and Savin (1997), Jones, Manuelli, and McGrattan (2003), Greenwood, Seshadri, and Yorukoglu (2005).
} 
production. Overall, leisure time measured as the difference between time available and time devoted to non-leisure activities (such as work, school, home production, commuting and personal care time) changed little for both males and females since 1960 (see Figure 5 in Ramey and Francis (2009)). In contrast, Aguiar and Hurst (2007) document that, over a similar time period, leisure time has increased anywhere between four to eight hours per week for males and females of working age (see Table III in their paper). As pointed out by Ramey and Francis, some of the differences in estimates are due to different definitions of leisure. Both studies document that average time spent in home production in the U.S. declined since the $1960 s$.

We conclude that a model where leisure time takes into account various forms of nonmarket activity may help improve the predictions of our model for U.S. hours and the labor wedge. However, the evidence seems mixed. The larger-end estimates provided by Aguiar and Hurst (2007) show an increase in leisure time of about 15 percent between 1965 and 2003, while the estimates provided by Ramey and Francis (2009) show an increase of barely 2 percent.

\section{Conclusion}

From 1960 to 2007, average hours worked in the U.S. increased by about thirteen percent. This increase was driven by a very large increase of married women's hours, while single women's hours rose only slightly and hours of men declined. In order to examine these trends, we augment the standard growth model to allow for gender and marital status heterogeneity. We consider the impact of various exogenous factors on labor supply, the most important of which are changes in effective labor income taxes and changes in the gender wage gaps. Our baseline model can account for much of the observed increase in aggregate labor supply, and much of the changes in the different group's labor supply over time.

Building on the success of the model for labor supply, we assess the extent to which it is 
able to generate a trend decline in the labor wedge consistent with aggregate data for the U.S. economy. We measure the labor wedge in the model as the aggregate discrepancy between the marginal rate of substitution between consumption for leisure and the marginal product of labor. While shrinking gender wage gaps allow the model to generate a labor wedge that declines beginning in the early 1980s, we find that a non-negligible discrepancy remains. A lesson from our exercise is that, in order to fully understand the changes in the U.S. labor wedge since 1980s, our models need to simultaneously predict the observed increasing trend in the consumption to output ratio and the increase in labor supply. A key contribution of our work is to show that the labor wedge measured from a representative household model partly reflects imperfect household aggregation. We show that the labor wedge is partly due to non-distortionary factors such as the labor supply and relative productivities of men and women. In this paper, we have focused on long-run changes in the labor wedge and a particular split of the population by gender and marital status. However, a natural extension of our analysis is to examine recessions by considering how changes in various subgroups of the employed population with different productivities affects the labor wedge.

\section{A.1 Data Appendix}

Survey data: We use data from the IPUMS-CPS to construct our measures of average hours worked and the gender wage gap. The IPUMS-CPS is based on the March Current Population Survey and is available yearly since 1962 at http://cps.ipums.org/cps/. We use the following variables in our calculations:

- PERWT: person weight, $1962-2008$

- AGE: person's age at last birthday, $1962-2008$

- SEX: sex, $1962-2008$

- MARST: current marital status, $1962-2008$ 
- EMPSTAT: current employment status, $1962-2008$

- WKSWORK1: number of weeks worked last year, 1976 - 2008

- WKSWORK2: number of weeks worked last year, 1962 - 2008. This variable differs from WKSWORK1 in that responses are given in intervals: $1-13$ weeks; $14-26$ weeks; 27 - 39 weeks; $40-47$ weeks; $48-49$ weeks; and $50-52$ weeks

- HRSWORK: hours worked last week, $1962-2008$.

- INCWAGE: wage and salary income last year, $1962-2008$.

For each person, we construct total hours worked last year as the product of weeks worked and hours worked per week. Starting 1976, we use the variable WKSWORK1 to obtain weeks worked for each person. Prior to 1976, the survey provides only the variable WKSWORK2 which gives us an interval for the weeks worked for each person. In our calculations for years 1962 through 1975, we replace variable WKSWORK2 with an average number of weeks worked (given in equation 15) that is calculated based on variable WKSWORK1 as follows. We take variable WKSWORK1 and group persons according to their number of weeks worked into the same intervals provided in variable WKSWORK2. We then compute the average weeks worked for each of the six intervals from 1976 to 2008. For each interval, the averages obtained vary very little over time. For example, the average number of weeks worked for persons working between 1 and 13 weeks was roughly 8 for all years from 1976 to 2008 .

$$
\text { weeks worked, } 1962-1975=\left\{\begin{aligned}
8.0 & \text { if WKSWORK2 is } 1-13 \text { weeks } \\
21.7 & \text { if WKSWORK2 is } 14-26 \text { weeks } \\
33.7 & \text { if WKSWORK2 is } 27-39 \text { weeks } \\
42.6 & \text { if WKSWORK2 is } 40-47 \text { weeks } \\
48.3 & \text { if WKSWORK2 is } 48-49 \text { weeks } \\
51.9 & \text { if WKSWORK2 is } 50-52 \text { weeks }
\end{aligned}\right.
$$


We use variable INCWAGE to obtain the wage per hours for each person.

Next, we construct population, employment, average hours worked and median wage per hour for each of the following groups of the population: total population, married men, married women, single men, single women. Our measure of married couples includes the following categories from the variable MARST: "married, spouse present", "married, spouse absent" and "separated". We group the categories "divorced", "widowed" and "never married" under our measure of singles. We use population ages 20 to 64. We use the median wage per hour because it is not affected by changes in the top code. To construct employment we take all persons who were employed and at work during the reference week, all persons who were employed but not at work that week, and all persons in the Armed Forces $($ EMPSTAT $=10,12$ and 13, respectively). We construct hours worked by employed persons using all respondents that report EMPSTAT equal to 10 or 13. The average hours worked

per week are then given by: $h_{E} \cdot \frac{E}{N} \cdot \frac{1}{52}$, where $h_{E}$ are hours worked during the year by employed people, $E$ is the total number of employed persons, and $N$ is the total population. Our implicit assumption is that persons not at work during the reference week (i.e. people with EMPSTAT equal to 12) work similar yearly hours to those at work during the reference week.

The average hours worked we obtain for the total population are very similar to those reported by Cociuba, Ueberfeldt, and Prescott (2009). Our average hours worked for married and single individuals differ slightly from those reported by McGrattan and Rogerson (2008), who use population $25-64$.

National accounts and fixed assets data: We obtain these data from the Bureau of Economic Analysis. We make a few adjustments to the national accounts. We treat consumer durables as investment. We treat government military investment as government consumption and the remainder of government investment is treated as investment. We also remove sales taxes from the gross domestic product. 
Tax rates: We use data from the Organization for Economic Co-operation and Development to construct tax rates following the methodology of Mendoza, Razin, and Tesar (1994). We use Joines (1981) to extend the series of tax rates before 1970.

\section{A.2 Model Aggregate Intratemporal Condition}

Here, we derive the model's aggregate intratemporal condition. The model has four intratemporal equations for each type of consumer in the economy. We multiply each intratemporal condition by the fraction of consumers of that type and sum up. We obtain:

$$
\begin{aligned}
& \alpha\left(n_{p t} c_{m p t}+n_{p t} c_{f p t}+n_{m s t} c_{m s t}+n_{f s t} c_{f s t}\right)+\alpha \phi g_{t}\left(2 n_{p t}+n_{m s t}+n_{f s t}\right) \\
= & \left(1-\tau_{l t}\right) w_{t} n_{p t}\left(1-l_{m p t}\right)+\left(1-\tau_{l t}\right) w_{t} n_{p t}\left(1-\Gamma_{p t}\right)\left(1-l_{f p t}\right) \\
+ & \left(1-\tau_{l t}\right) w_{t} n_{m s t}\left(1-l_{m s t}\right)+\left(1-\tau_{l t}\right) w_{t} n_{f s t}\left(1-\Gamma_{s t}\right)\left(1-l_{f s t}\right)
\end{aligned}
$$

Equation (16) can also be written as $\alpha\left(c_{t}+\phi g_{t}\right)=\left(1-\tau_{l t}\right) w_{t} \Lambda_{t}$, where $c_{t} \equiv \frac{C_{t}}{N_{t}}$ denotes aggregate private consumption per person, and where $\Lambda_{t}$ is defined as below.

$$
\begin{aligned}
\Lambda_{t} \equiv & 2 n_{p t}+n_{m s t}+n_{f s t}-n_{p t} l_{m p t}+n_{p t}\left[-l_{f p t}-\Gamma_{p t}\left(1-l_{f p t}\right)\right]-n_{m s t} l_{m s t} \\
& +n_{f s t}\left[-l_{f s t}-\Gamma_{s t}\left(1-l_{f s t}\right)\right] \\
\Lambda_{t}= & 1-\left(n_{p t} l_{m p t}+n_{p t} l_{f p t}+n_{m s t} l_{m s t}+n_{f s t} l_{f s t}\right)-n_{p t} \Gamma_{p t}\left(1-l_{f p t}\right)-n_{f s t} \Gamma_{s t}\left(1-l_{f s t}\right)
\end{aligned}
$$

In the last expression we have used $2 n_{p t}+n_{m s t}+n_{f s t}=\left(2 N_{p t}+N_{m s t}+N_{f s t}\right) / N_{t}=1$.

Let $l_{t}$ denote aggregate hours worked per person: $l_{t} \equiv n_{p t} l_{m p t}+n_{p t} l_{f p t}+n_{m s t} l_{m s t}+n_{f s t} l_{f s t}$. The aggregate intratemporal equation becomes:

$$
\alpha\left(c_{t}+\phi g_{t}\right)=\left(1-\tau_{l t}\right) w_{t}\left[1-l_{t}-n_{p t} \Gamma_{p t}\left(1-l_{f p t}\right)-n_{f s t} \Gamma_{s t}\left(1-l_{f s t}\right)\right]
$$


We divide both sides by $\left(1-l_{t}\right)$ and use $w_{t}=(1-\theta) y_{t} / \tilde{l}_{t}$ to get:

$$
\frac{\alpha\left(c_{t}+\phi g_{t}\right)}{1-l_{t}}=\left(1-\tau_{l t}\right)\left(1-\frac{n_{p t} \Gamma_{p t}\left(1-l_{f p t}\right)+n_{f s t} \Gamma_{s t}\left(1-l_{f s t}\right)}{1-l_{t}}\right) \frac{(1-\theta) y_{t}}{\tilde{l}_{t}}
$$

\section{References}

Aguiar, M., and E. Hurst (2007): "Measuring Trends in Leisure: The Allocation of Time Over Five Decades," Quarterly Journal of Economics, 122(3), 969-1006.

Ahearne, A., F. Kydland, And M. A. Wynne (2006): "Ireland's Great Depression," Economic and Social Review, 37(2), 215-243.

Attanasio, O., H. Low, and V. Sánchez-Marcos (2008): "Explaining Changes in Female Labor Supply in a Life-Cycle Model," American Economic Review, 98(4), 15171552.

Bar, M., And O. Leukhina (2008): "Accounting for Changes in Labor Force Participation of Married Women: The Case of the U.S. since 1959.," working manuscript, University of North Carolina.

(2009): "To Work or Not to Work: Did Tax Reforms Affect Labor Force Participation of Married Couples?," The B.E. Journal of Macroeconomics, 9(1), Article 28.

Benhabib, J., R. Rogerson, and R. Wright (1991): "Homework in Macroeconomics: Household Production and Aggregate Fluctuations," Journal of Political Economy, 99(6), 1166-1187.

Chakraborty, S. (2009): "The Boom and the Bust of the Japanese Economy: A quantitative look at the period 1980 to 2000," Japan and the World Economy, 21(1), 116-131.

Chang, Y., And S.-B. KIM (2007): "Heterogeneity and Aggregation: Implications for Labor-Market Fluctuations," American Economic Review, 97(5), 1939-1956. 
Chari, V., P. J. Kehoe, and E. R. McGrattan (2007): "Business Cycle Accounting," Econometrica, 75(3), 781-836.

Cociuba, S. E., and A. Ueberfeldt (2008): "Driving Forces of the Canadian Economy: An Accounting Exercise," Bank of Canada Working Paper 08-14, Federal Reserve Bank of Dallas Globalization and Monetary Policy Institute Working Paper 6.

Cociuba, S. E., A. Ueberfeldt, and E. C. Prescott (2009): "U.S. Hours and Productivity Behavior Using CPS Hours Worked Data: 1947-III to 2009-II," Working Paper, Federal Reserve Bank of Dallas.

Erosa, A., L. Fuster, and D. Restuccia (2002): "Fertility Decisions and Gender Differences in Labor Turnover, Employment, and Wages," Review of Economic Dynamics, $5(4), 856-891$.

(2005): "A Quantitative Theory of the Gender Gap in Wages," University of Toronto, Working Paper.

Goldin, C. (1992): Understanding the Gender Gap: An Economic History of American Women, NBER Series on Long-Term Factors in Economic Development. Oxford University Press.

Greenwood, J., A. Seshadri, and M. Yorukoglu (2005): "Engines of Liberation," Review of Economic Studies, 72(1), 109-133.

Hall, R. E. (1997): "Macroeconomic Fluctuations and the Allocation of Time," Journal of Labor Economics, 15(1), S223-S250.

Ingram, B. F., N. R. Kocherlakota, and N. Savin (1997): "Using theory for measurement: An analysis of the cyclical behavior of home production," Journal of Monetary Economics, 40, 435-456. 
Joines, D. H. (1981): "Estimates of Effective Marginal Tax Rates on Factor Incomes," The Journal of Business, 54(2), 191-226.

Jones, L. E., R. E. Manuelli, and E. R. McGrattan (2003): "Why Are Married Women Working So Much?," Federal Reserve Bank of Minneapolis Staff Report $31 \%$.

Kersting, E. (2008): "The 1980s Recession in the UK: A Business Cycle Accounting Perspective," Review of Economic Dynamics, 11(1), 179-191.

Kryvtsov, O., And A. Ueberfeldt (2007): "Schooling, Inequality and Government Policy," Bank of Canada Working Paper 200\%-12.

McGrattan, E. R., And E. C. Prescott (2010): "Unmeasured Investment and the Puzzling U.S. Boom in the 1990s," American Economic Journal: Macroeconomics, forthcoming.

McGrattan, E. R., and R. Rogerson (2008): "Changes in the Distribution of Family Hours Worked Since 1950," in Frontiers of Family Economics, vol. 1, pp. 115-138. Emerald Group Publishing Limited.

Mendoza, E. G., A. Razin, and L. Tesar (1994): "Effective Tax Rates in Macroeconomics: Cross Country Estimates of Tax Rates on Factor Incomes and Consumption," Journal of Monetary Economics, 34, 297-323.

Mulligan, C. B. (2002): "A Century of Labor-Leisure Distortions," NBER Working Paper Series, No. 8774.

Ohanian, L., A. Raffo, and R. Rogerson (2008): "Long-term changes in labor supply and taxes: Evidence from OECD countries, 1956-2004," Journal of Monetary Economics, $55(8), 1353-1362$.

PARKIn, M. (1988): "A Method for Determining Whether Parameters in Aggregative Models are Structural," Carnegie-Rochester Conference Series on Public Policy, 29, 215-252. 
Prescott, E. C. (2004): "Why Do Americans Work So Much More Than Europeans?," Federal Reserve Bank of Minneapolis Quarterly Review, 28(1), 2-13.

Ragan, K. S. (2006): "Taxes, Transfers, and Time Use: Fiscal Policy in a Household Production Model," PhD. dissertation, University of Chicago.

Ramey, V., and N. Francis (2009): "A Century of Work and Leisure," American Economic Journal: Macroeconomics, 1(2), 189-224.

Rogerson, R. (2007): "Taxation and market work: is Scandinavia an outlier?," Economic Theory, 32, 59-85.

Shimer, R. (2009): "Convergence in Macroeconomics: The Labor Wedge," American Economic Journal: Macroeconomics, 1(1), 280-297.

(2010): Labor Markets and Business Cycles. Princeton University Press. 
Figure 1: Hours Worked and The Labor Wedge Measured from U.S. Data
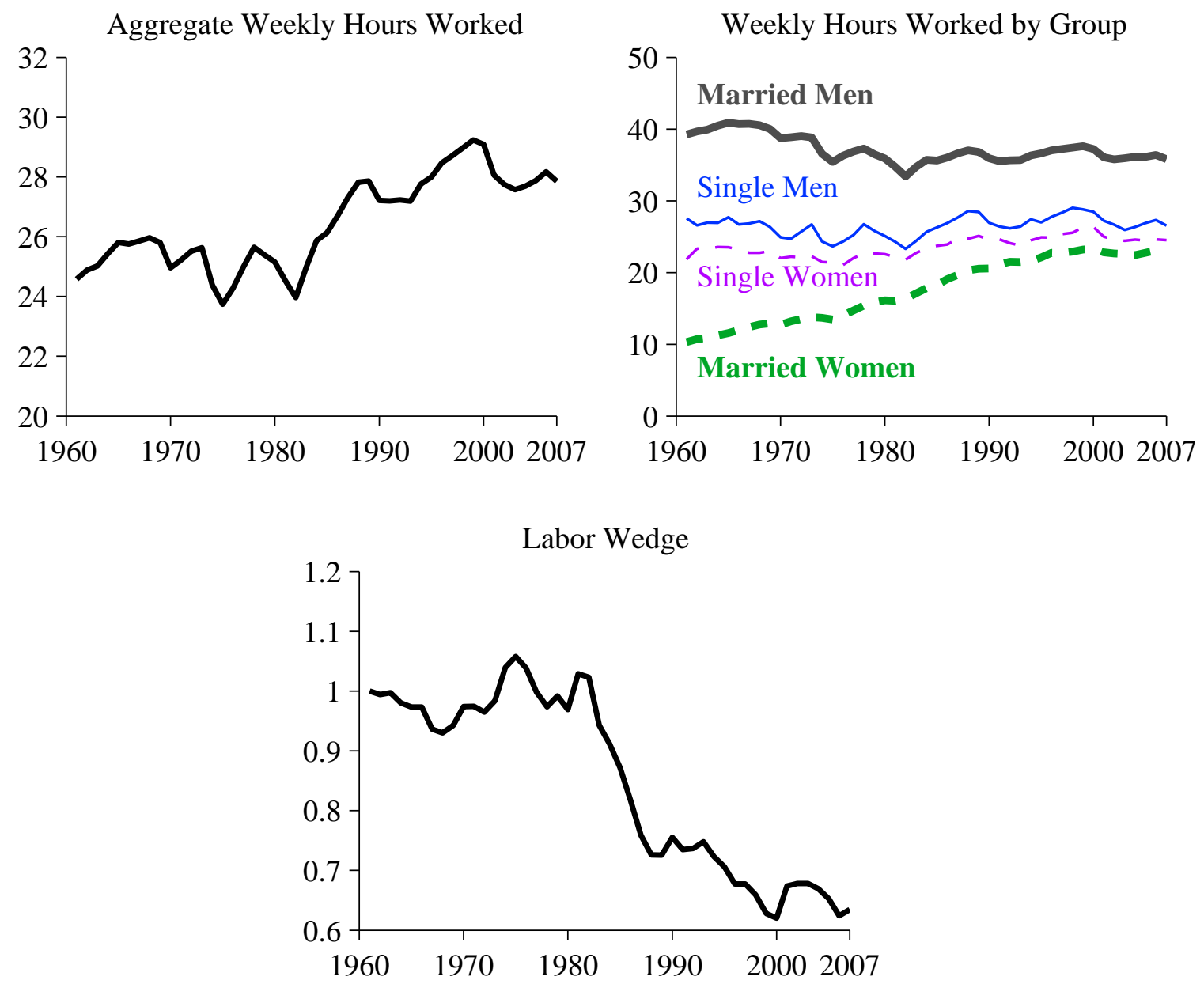
Figure 2: Time-Varying Model Inputs Measured from U.S. Data
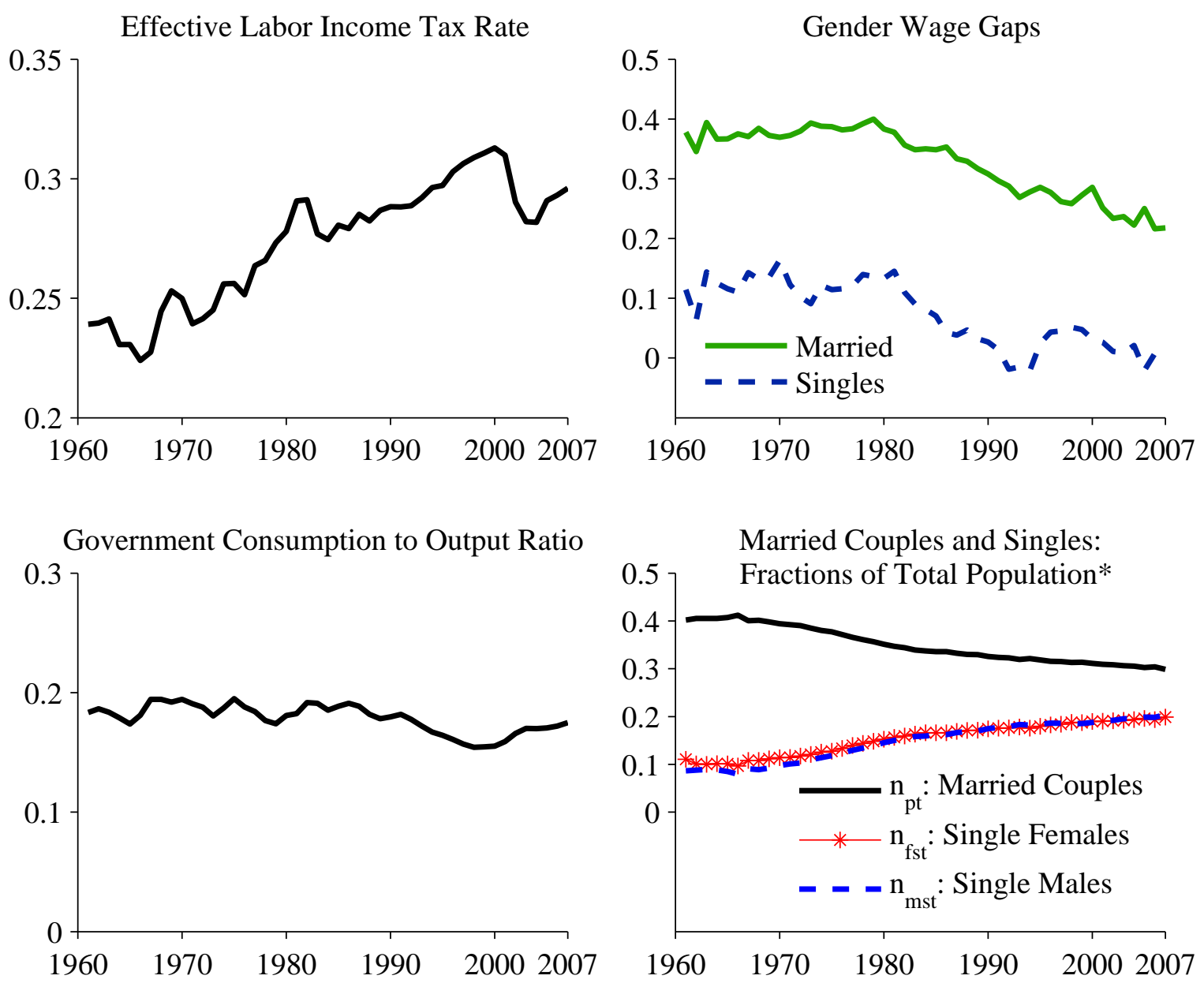

*Note: $2 \cdot \mathrm{n}_{\mathrm{pt}}+\mathrm{n}_{\mathrm{fst}}+\mathrm{n}_{\mathrm{mst}}=1$ 
Figure 3: Hours and the Labor Wedge in Data and Baseline Model
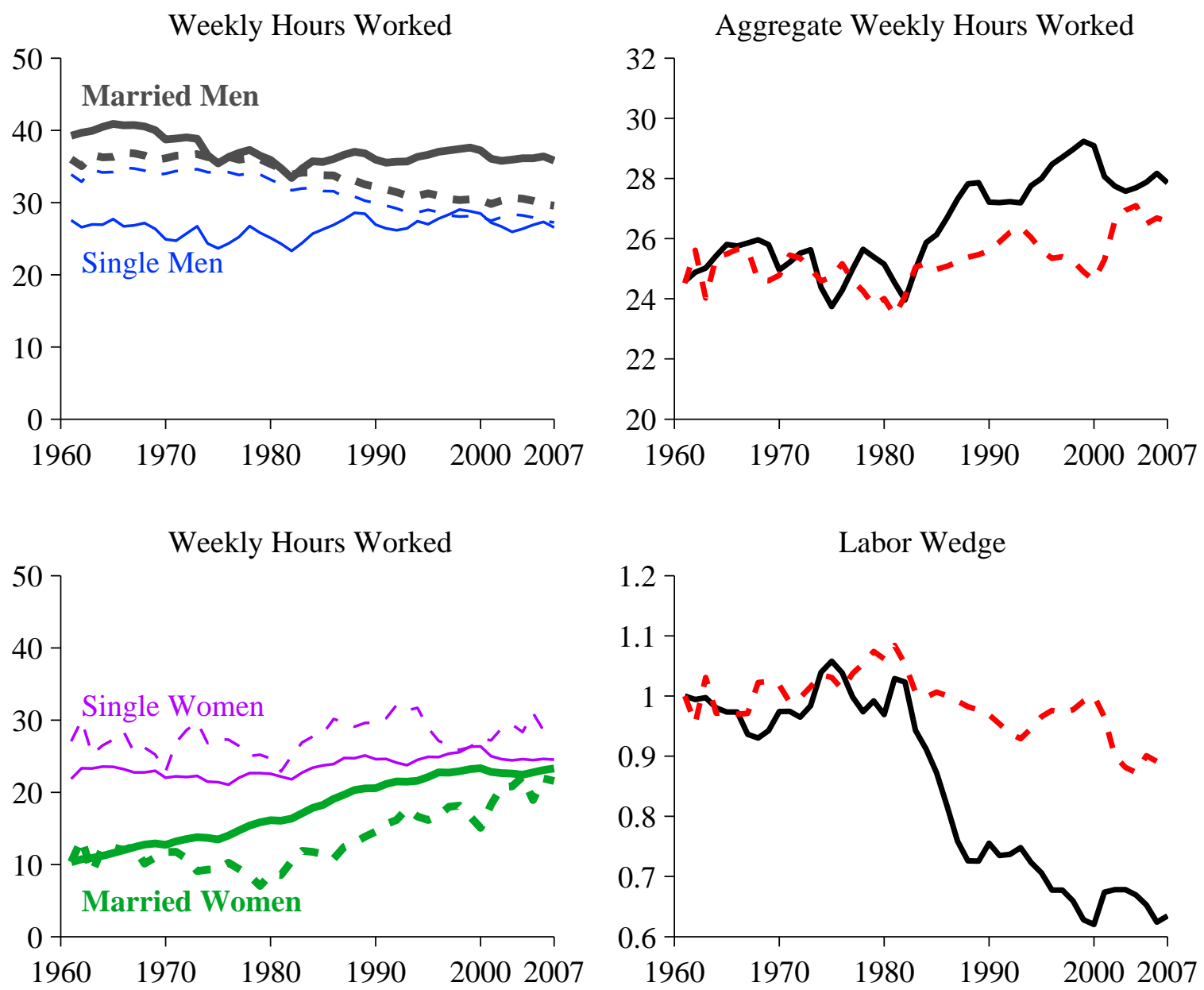

Legend

- Data
- - Baseline Model 
Figure 4: Model with Shrinking Gender Wage Gaps Only
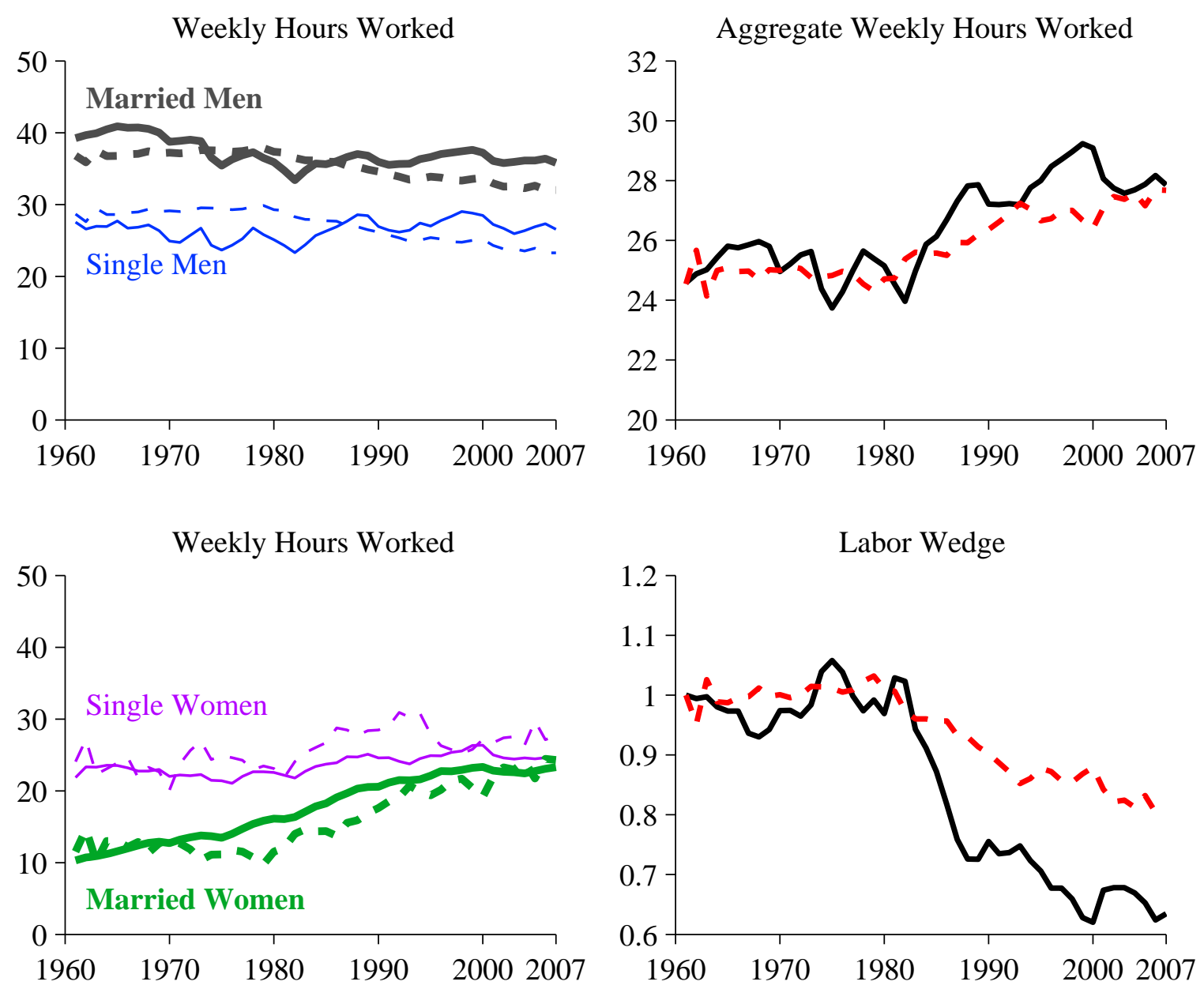

Legend

Data

- - - Model with Time-Varying Gender Wage Gaps Only 
Figure 5: Model with Time-Varying Taxes, Government Consumption and FraCtions OF HOUSEHOLDS
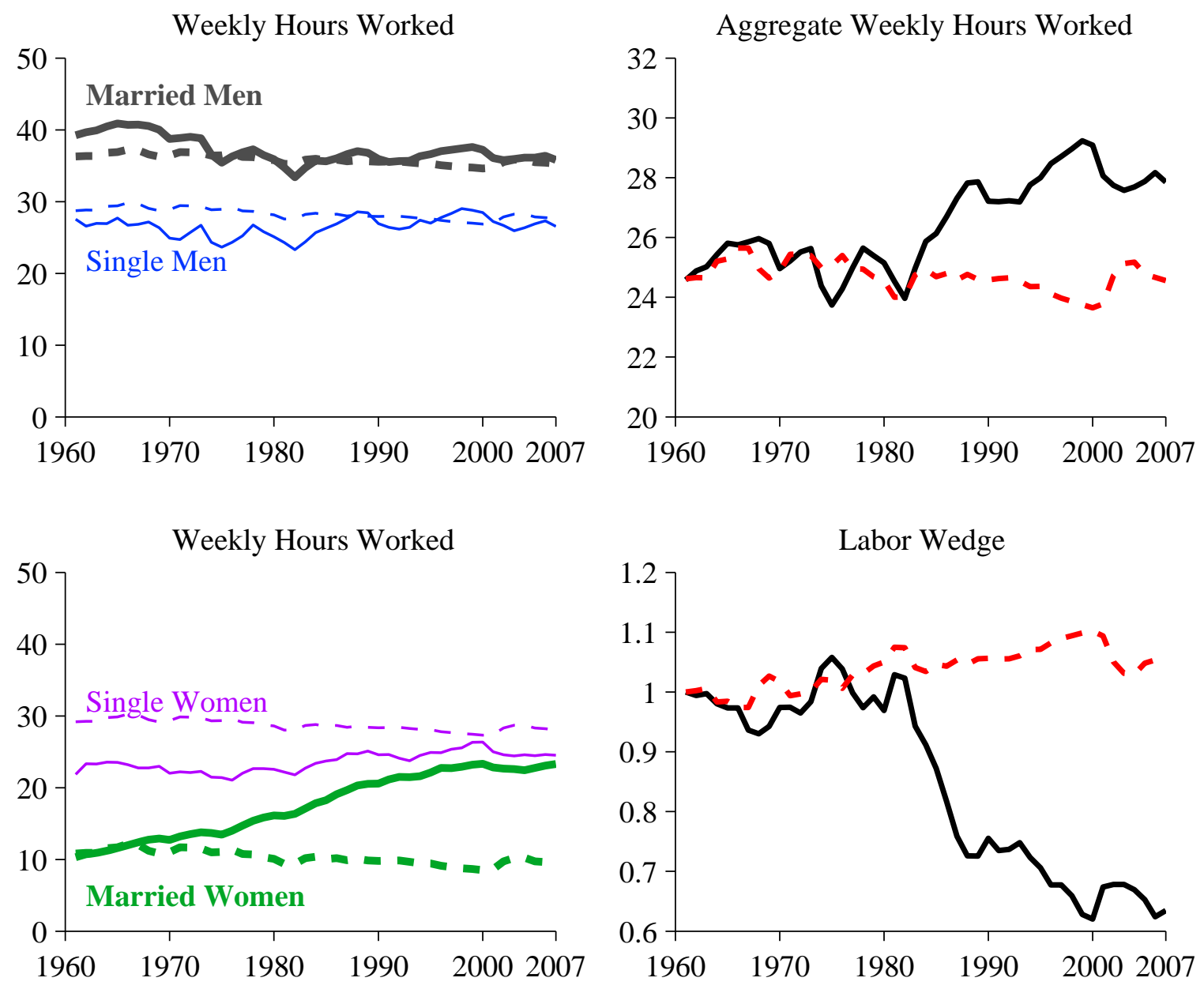

Legend

Data

- - Model with All Time-Varying Inputs Except Gender Wage Gaps 
Figure 6: Model with All Time-VArying Inputs and Childcare Costs

Aggregate Weekly Hours Worked

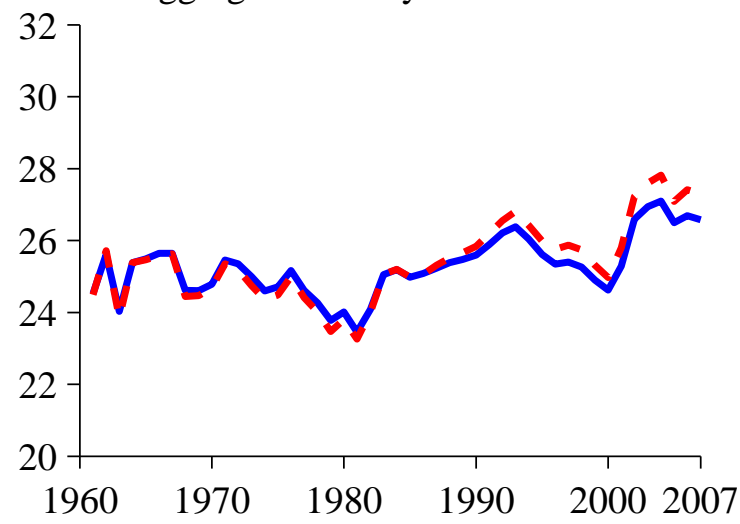

Weekly Hours Worked: Married Men

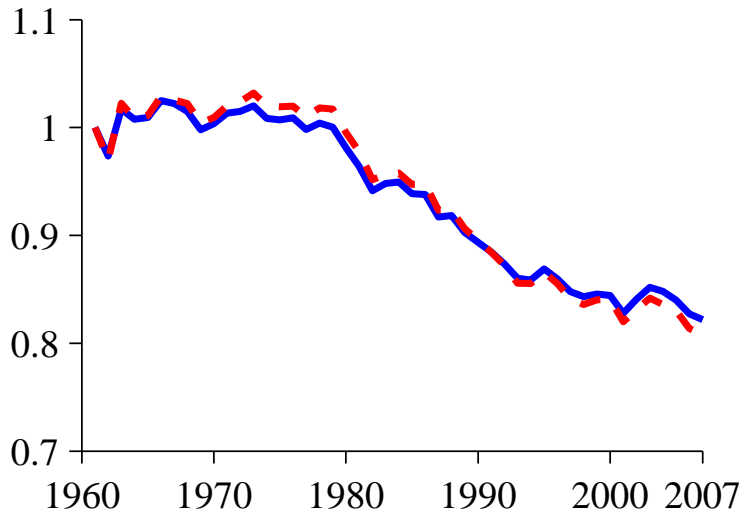

Weekly Hours Worked: Single Women

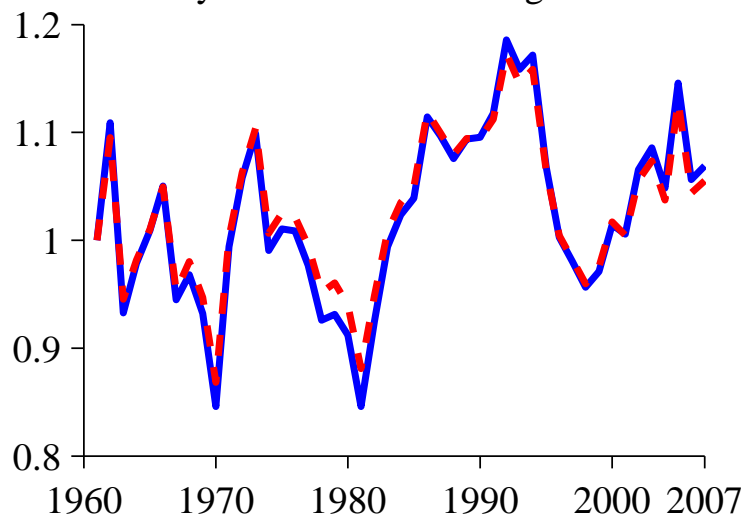

Labor Wedge

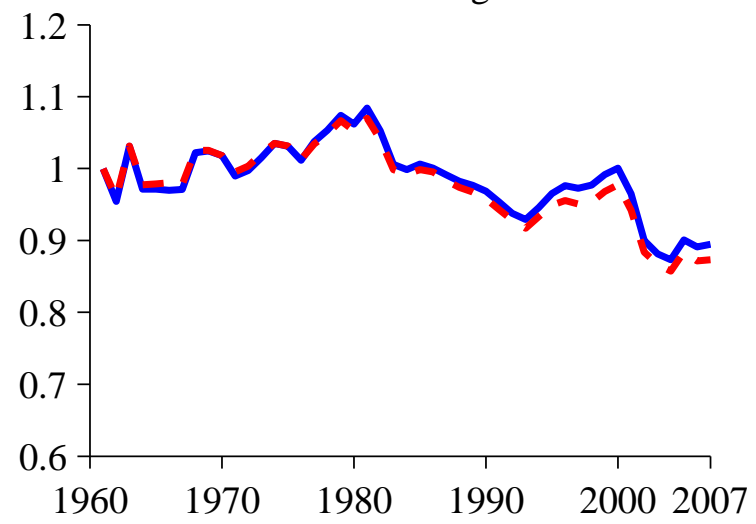

Weekly Hours Worked: Single Men

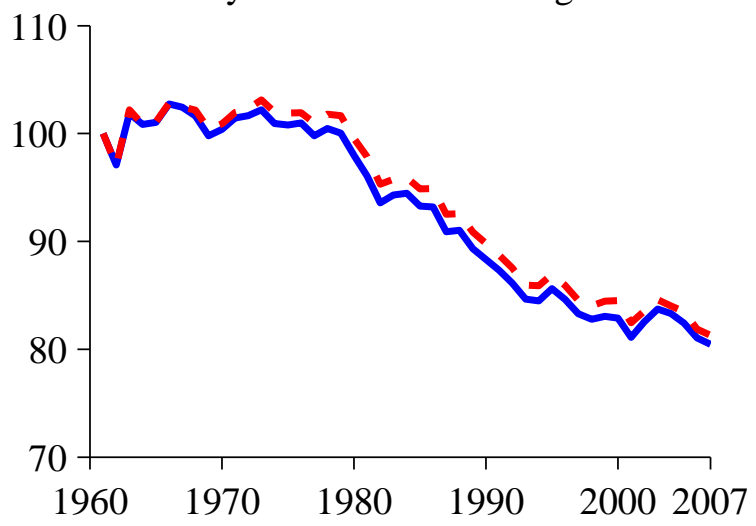

Weekly Hours Worked: Married Women

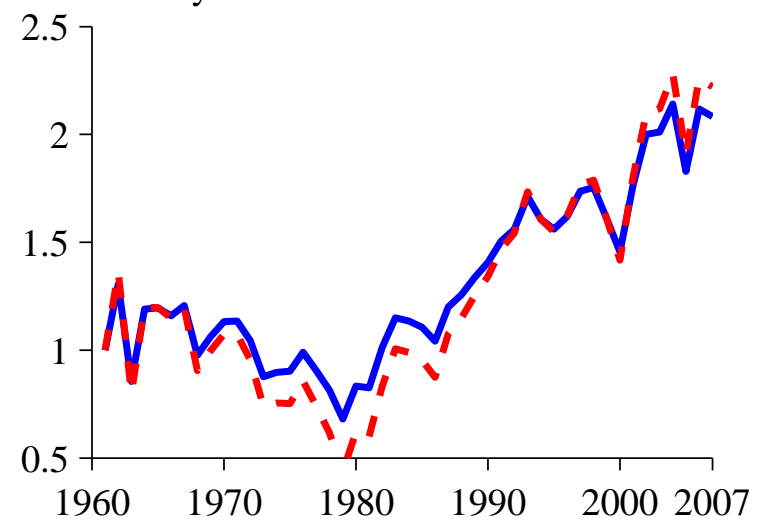

Legend

Baseline Model

- - - Model with Reductions in Childcare costs 
Table 1: Heterogeneity and the Labor Wedge: Numerical Illustration

\begin{tabular}{|c|c|c|c|c|c|}
\hline & \multicolumn{2}{|c|}{ Households } & \multicolumn{3}{|c|}{ Computations $^{\dagger}$} \\
\hline & TyPe 1 & TyPe 2 & $l$ & $\tilde{l}$ & $\Delta$ \\
\hline CASE 1: LARGE DIFFERENCES IN $l_{j}$ AND $z_{j}$ & & & 0.25 & 0.235 & 0.128 \\
\hline Fraction of total population, $N_{j} / N$ & $1 / 2$ & $1 / 2$ & & & \\
\hline Hours worked per week, $l_{j}$ & 0.40 & 0.10 & & & \\
\hline Productivity, $z_{j}$ & 1.00 & 0.70 & & & \\
\hline Case 2: Small differences in $l_{j}$ And $z_{j}$ & & & 0.35 & 0.328 & 0.018 \\
\hline Fraction of total population, $N_{j} / N$ & $1 / 2$ & $1 / 2$ & & & \\
\hline Hours worked per week, $l_{j}$ & 0.40 & 0.30 & & & \\
\hline Productivity, $z_{j}$ & 1.00 & 0.85 & & & \\
\hline Case 3: Differences in $z_{j}$ Only & & & 0.40 & 0.34 & 0 \\
\hline Fraction of total population, $N_{j} / N$ & $1 / 2$ & $1 / 2$ & & & \\
\hline Hours worked per week, $l_{j}$ & 0.40 & 0.40 & & & \\
\hline Productivity, $z_{j}$ & 1.00 & 0.70 & & & \\
\hline Case 4: Differences in $l_{j}$ Only & & & 0.25 & 0.25 & 0 \\
\hline Fraction of total population, $N_{j} / N$ & $1 / 2$ & $1 / 2$ & & & \\
\hline Hours worked per week, $l_{j}$ & 0.40 & 0.10 & & & \\
\hline Productivity, $z_{j}$ & 1.00 & 1.00 & & & \\
\hline
\end{tabular}

${ }^{\dagger}$ The aggregate hours worked per person are given by $l=\sum_{j}\left(l_{j} N_{j}\right) / N$ and the aggregate effective labor per person is given by $\tilde{l}=\sum_{j}\left(z_{j} l_{j} N_{j}\right) / N$. The labor wedge, $\Delta$, is computed using equation (3), keeping in mind that $\tau_{l}$ is zero in our numerical illustration. 
Table 2: Baseline Model Parameters and Time Varying Inputs

\begin{tabular}{ll}
\hline \hline & VALUES \\
PARAMETERS & $\eta=1.013$ \\
Population growth & $\gamma=1.017$ \\
Technology growth & $\theta=0.33$ \\
Capital income share & $\delta=0.05$ \\
Depreciation of capital & $\tau_{k}=0.40$ \\
Capital income tax rate & $\beta=0.98$ \\
Discount factor & $\sigma=1.00$ \\
Intertemporal substitution & $\phi=1.00$ \\
Government consumption parameter & $\alpha=1.58$ \\
Leisure parameter & $\lambda_{f}=0.465, \lambda_{m}=1-\lambda_{f}$ \\
Weights in utility, $\lambda_{f} U_{f}+\lambda_{m} U_{m}$ & $\mu=0$ \\
Share of gender gap due to & \\
productivity differences & VALUES $($ See Figure 2$)$ \\
TimE-VARYING INPUTS & $\tau_{l t}=\frac{\text { Consumption Tax }+ \text { Labor Tax }}{1+\text { Consumption Tax }}$ \\
Effective labor income tax rate & $\Gamma_{i t}=1-\frac{\text { hourly wage for females at } t}{\text { hourly wage for males at } t}, i \in\{p, s\}$ \\
Gender wage gaps & $\frac{G_{t}}{Y_{t}}$ from NIPA data \\
$\quad$ for married $(p)$ and singles $(s)$ & $n_{p t}=\frac{N_{p t}}{N_{t}}, n_{f s t}=\frac{N_{f s t}}{N_{t}}, n_{m s t}=\frac{N_{m s t}}{N_{t}}$ from CPS \\
Government consumption to output ratio & \\
Fractions of married and single households & \\
\hline \hline
\end{tabular}


Table 3: Baseline Model: Changes in Weekly Hours Worked, 1961 to 2007

\begin{tabular}{|c|c|c|c|c|}
\hline \multicolumn{5}{|c|}{ Changes in Aggregate Weekly Hours Worked ${ }^{\dagger}$ : } \\
\hline \multicolumn{5}{|c|}{$l_{2007} / l_{1961}=\sum_{\nu \in\{m p, m s, f s, f p\}}\left(\frac{n_{\nu 2007}}{n_{\nu 1961}} \cdot \frac{n_{\nu 1961} \cdot l_{\nu 1961}}{l_{1961}} \cdot \frac{l_{\nu 2007}}{l_{\nu 1961}}\right)$} \\
\hline \multicolumn{5}{|l|}{ DATA: $l_{2007} / l_{1961}=1.133$} \\
\hline & \multicolumn{2}{|c|}{ Male } & \multicolumn{2}{|c|}{ Female } \\
\hline CONTRIBUtion OF GROUP $\nu$ & Married & Single & Single & Married \\
\hline Change in fraction of population, $\frac{n_{\nu 2007}}{n_{\nu 1961}}$ & $0.743^{*}$ & $2.364^{*}$ & $1.803^{*}$ & $0.743^{*}$ \\
\hline Share of aggregate hours in $1961, \frac{n_{\nu 1961} \cdot l_{\nu 1961}}{l_{1961}}$ & 0.641 & 0.097 & 0.098 & 0.169 \\
\hline Change in hours worked, $\frac{l_{\nu 2007}}{l_{\nu 1961}}$ & 0.913 & 0.964 & 1.122 & 2.258 \\
\hline \multicolumn{5}{|l|}{ BASELINE ModeL: $l_{\mathbf{2 0 0 7}} / l_{\mathbf{1 9 6 1}}=\mathbf{1 . 0 8 4}$} \\
\hline & \multicolumn{2}{|c|}{ Male } & \multicolumn{2}{|c|}{ Female } \\
\hline CONTRIBUtion OF GROUP $\nu$ & Married & Single & Single & Married \\
\hline Change in fraction of population, $\frac{n_{\nu 2007}}{n_{\nu 1961}}$ & $0.743^{*}$ & $2.364^{*}$ & $1.803^{*}$ & $0.743^{*}$ \\
\hline Share of aggregate hours in $1961, \frac{n_{\nu 1961} \cdot l_{\nu 1961}}{l_{1961}}$ & 0.589 & 0.119 & 0.122 & 0.169 \\
\hline Change in hours worked, $\frac{l_{\nu 2007}}{l_{\nu 1961}}$ & 0.822 & 0.804 & 1.069 & 2.083 \\
\hline
\end{tabular}

${ }^{\dagger}$ Changes in aggregate hours are decomposed into the contributions of the different groups in the population: married males $(m p)$, single males $(m s)$, single females $(f s)$ and married females $(f p)$. In the formula in this table, note that $\mathrm{N}_{m p t}=\mathrm{N}_{f p t}=\mathrm{N}_{p t}$ for all $t .{ }^{*}$ The fractions of married couples and singles in the total population are exogenous inputs into the baseline model, hence the model matches the changes in these fractions by construction. 
Table 4: Baseline Model: Changes in the Labor Factor, 1961 to $2007^{\dagger}$

LABOR FACTOR, $1-\Delta_{t} \equiv \frac{\alpha}{(1-\theta)} \frac{\left(c_{t}+g_{t}\right)}{y_{t}} \frac{l_{t}}{1-l_{t}}=\left(1-\tau_{l t}\right)\left(1-\frac{n_{p t} \Gamma_{p t}\left(1-l_{f p t}\right)+n_{f s t} \Gamma_{s t}\left(1-l_{f s t}\right)}{1-l_{t}}\right) \frac{l_{t}}{\tilde{l}_{t}}$

\section{Changes in Labor Factor and Components}

Labor Factor, $1-\Delta_{t}$

Consumption to output ratio, $\frac{\left(c_{t}+g_{t}\right)}{y_{t}}$

Aggregate labor component, $\frac{l_{t}}{1-l_{t}}$

Tax component, $1-\tau_{l t}$

Female labor component, $1-\frac{n_{p t} \Gamma_{p t}\left(1-l_{f p t}\right)+n_{f s t} \Gamma_{s t}\left(1-l_{f s t}\right)}{1-l_{t}}$

Labor input to effective labor ratio, $l_{t} / \tilde{l}_{t}$

\begin{tabular}{cl} 
Baseline Model $^{a}$ & Data $^{b}$ \\
\hline 1.0661 & 1.2660 \\
\hline 0.9570 & 1.0687 \\
1.1141 & 1.1847 \\
\hline 0.9252 & 0.9252 \\
1.1523 & 1.1543 \\
1 &
\end{tabular}

${ }^{\dagger}$ The expressions for the model's labor factor are derived in Section 3.1.2 (see Equations (1) and (12)). ${ }^{a}$ The column "Baseline Model" reports calculations using data generated from the baseline model. This model attributes all of the gender wage gap to discrimination, so there are no differences between the labor input, $l_{t}$, and effective labor, $\tilde{l}_{t}$. ${ }^{b}$ The column "Data" shows the changes in the labor factor and components as measured using U.S. data. To measure the labor factor, we use U.S. data on private consumption, government consumption, output and aggregate hours worked. Notice that $\alpha$ and $\theta$ affect the level of the labor factor, but not its changes over time. For other calculations reported in the column "Data", we also use data on female hours worked, taxes, gender wage gaps and fractions of single and married women in the total population. 
Table 5: Comparison: Baseline Model and Other Experiments ${ }^{\dagger}$

\begin{tabular}{|c|c|c|c|c|}
\hline & \multicolumn{2}{|c|}{ PERCENT CHANGE: } & \multicolumn{2}{|c|}{$1961-2007$} \\
\hline & $l_{t}$ & $l_{f p t}$ & $\Delta_{t}$ & $\frac{c_{t}+g_{t}}{y_{t}}$ \\
\hline DATA & 13.3 & 125.8 & -36.5 & 6.9 \\
\hline \multicolumn{5}{|l|}{ Experiments With Baseline Calibration } \\
\hline Baseline Model $^{*}$ & 8.4 & 108.3 & -10.5 & -4.3 \\
\hline \multicolumn{5}{|l|}{ One Time-Varying Input Only } \\
\hline Gender wage gaps* & 12.7 & 110.8 & -19.6 & -4.6 \\
\hline Effective labor income taxes & -3.3 & -7.7 & 12.1 & -3.2 \\
\hline Government consumption & 2.7 & 6.4 & 0.0 & -3.5 \\
\hline Fractions of households & 5.9 & 4.2 & -6.8 & -3.5 \\
\hline All Inputs Except Gender Wage Gaps* & -0.3 & -13.0 & 5.7 & -3.2 \\
\hline \multicolumn{5}{|c|}{ Other Experiments: All Time-Varying Inputs } \\
\hline Gender Gaps Due to Productivity $(\mu=1)$ & 7.4 & 108.8 & -7.8 & -5.6 \\
\hline Reductions in Childcare Costs* & 11.4 & 122.0 & -12.7 & -5.1 \\
\hline
\end{tabular}

\footnotetext{
${ }^{\dagger}$ We perform a number of experiments under the baseline calibration. In the experiments with only a subset of time-varying inputs, the households' lump-sum transfers are distributed in the same proportions as in the baseline model. Recalibrating the transfers does not change the results significantly. In the experiment with $\mu=1$ and the experiment with childcare costs, we recalibrate $\alpha$ and $\lambda_{f}$ (to match the same targets on hours worked as in the baseline calibration), but leave all other parameters unchanged. ${ }^{*}$ The results from experiments marked with a star are also plotted in Figures 3, 4, 5 and 6 respectively.
} 